\title{
Iron profiles and speciation of the upper water column at the Bermuda Atlantic Time-series Study site: a model based sensitivity study
}

\author{
L. Weber ${ }^{1}$, C. Völker ${ }^{2}$, A. Oschlies ${ }^{3}$, and H. Burchard ${ }^{4}$ \\ ${ }^{1}$ National Oceanography Centre, Southampton, UK \\ ${ }^{2}$ Alfred-Wegener-Institut für Polar- und Meeresforschung, Bremerhaven, Germany \\ ${ }^{3}$ Leibniz-Institut für Meereswissenschaften, Kiel, Germany \\ ${ }^{4}$ Institut für Ostseeforschung Warnemünde, Germany
}

Received: 14 March 2007 - Published in Biogeosciences Discuss.: 22 March 2007

Revised: 16 August 2007 - Accepted: 22 August 2007 - Published: 23 August 2007

\begin{abstract}
A one-dimensional model of the biogeochemistry and speciation of iron is coupled with the General Ocean Turbulence Model (GOTM) and a NPZD-type ecosystem model. The model is able to simulate the temporal patterns and vertical profiles of dissolved iron $(\mathrm{dFe})$ in the upper ocean at the Bermuda Atlantic Time-series Study site reasonably well. Subsurface model profiles strongly depend on the parameter values chosen for the loss processes for iron, colloidal aggregation and scavenging onto particles. Estimates for these parameters based on observations in particle-rich waters result in depletion of dFe. A high stability constant of ironbinding organic ligands is required to reproduce the observed degree of organic complexation below the mixed layer. The scavenging residence time for iron in the model is shortest in spring and summer, because of the larger abundance of particles, and increases with depth towards values on the order of a hundred years. A solubility of atmospherically deposited iron higher than $2 \%$ lead to $\mathrm{dFe}$ concentrations incompatible with observations. Despite neglecting ultraviolet radiation, the model produces diurnal variations and mean vertical profiles of $\mathrm{H}_{2} \mathrm{O}_{2}$ and iron species that are in good agreement with observations.
\end{abstract}

\section{Introduction}

The recognition of the role of iron in limiting marine primary production has lead to attempts to measure the distribution and bioavailability of iron in the world's oceans (Johnson et al., 1997). Typically, total dissolved iron (defined as passing through a $0.2 \mu \mathrm{m}$ or a $0.4 \mu \mathrm{m}$ filter) is measured. A number of recent studies have enhanced our understand-

Correspondence to: L. Weber

(1lw@noc.soton.ac.uk) ing of many of the processes that influence the speciation of iron, such as organic complexation (Gledhill and van den Berg, 1994; Van den Berg, 1995; Wu and Luther III, 1995; Rue and Bruland, 1995; Witter and Luther III, 1998; Witter et al., 2000), photochemical processes (Johnson et al., 1994; Emmenegger et al., 2001; Barbeau et al., 2003; Rijkenberg et al., 2004), redox reactions with peroxides (Voelker and Sedlak, 1995) and interactions with colloids and particle surfaces (Johnson et al., 1994; Wen et al., 1997). However, there are still many unknowns in the complex iron biochemistry in seawater due to the difficulty of direct measurement of chemical iron species in situ.

Numerical biogeochemical-physical models are now able to simulate the main patterns of total dissolved iron in the ocean (Dutkiewicz et al., 2005), but indicate that the details and in particular the climate sensitivity of so called "high nutrient-low chlorophyll" (HNLC) regions, are strongly dependent on the way the iron chemistry is parameterised (Parekh et al., 2004). These models are typically forced by annual mean dust inputs (Mahowald et al., 2003) and have a simplified description of the marine iron chemistry that primarily aims at reproducing the scavenging removal of iron in the deep ocean and that is not adequate to simulate the response to the episodic nature of iron input by individual dust deposition events.

Modelling of iron cycling between its various species has recently been refined by Rose and Waite (2003) for coastal waters and by Weber et al. (2005) for the open ocean surface mixed layer. Rose and Waite (2003) focused on the chemistry of iron in short term experiments. In contrast, Weber et al. (2005) used a slightly less complex zero-dimensional model for iron chemistry coupled to an ecosystem model to study iron biogeochemistry in the mixed layer at the Bermuda Atlantic Time-series Station (BATS) site. This model describes

Published by Copernicus Publications on behalf of the European Geosciences Union. 
the cycling of iron between its various physical (dissolved, colloidal, particulate) and chemical (redox state and organic complexation) species and is influenced by atmospheric dust deposition, photochemistry, organic complexation, colloid formation and aggregation as well as uptake and release by marine biota. Weber et al. (2005) achieved results close to observed dissolved iron concentrations in the mixed layer. In contrast to the simple global speciation models, the model resolves processes with short time-scales, such as photochemical cycling and the rapid disappearance of iron after pulsed deposition events. However, the model contains some parameters, especially those for scavenging, colloid formation and aggregation that are not very well known. It was shown that these parameters have a strong influence on the vertical fluxes of iron, but, due to the limitations of a zerodimensional model, do not affect the mixed-layer concentrations of dissolved Fe strongly. This means that these parameters remained basically unconstrained.

In this study we describe an one-dimensional extension of the zero-dimensional model by Weber et al. (2005). In contrast to the zero-dimensional model, the one-dimensional approach allows an analysis of the depth dependency of the processes determining iron speciation and fluxes. Especially photochemical processes and biological activity can lead to vertical concentration gradients even within the surface mixed layer, which might influence the residence time and bioavailability of iron.

A couple of studies measured dissolved iron (dFe) profiles at the BATS site (Sedwick et al., 2005; Wu and Boyle, 2002; Wu et al., 2001; Wu and Boyle, 1998; Wu and Luther III, 1994), where dFe refers to $0.4 \mu \mathrm{m}$-filtered samples. Furthermore $\mathrm{Wu}$ et al. (2001) distinguished between soluble (0.02 $\mu \mathrm{m}$-filtered samples) and colloidal iron $(0.02-0.4 \mu \mathrm{m})$. Data reveal strong seasonal changes of $\mathrm{dFe}$ concentrations ([dFe]) in surface waters, with high concentrations in summer (up to $2 \mathrm{nM}$ ) (Sedwick et al., 2005) and low concentrations in spring (down to $0.1 \mathrm{nM}$ ) (Wu and Boyle, 2002; Sedwick et al., 2005). The summer dissolved iron profiles of the different studies consistently show pronounced near surface maxima in $[\mathrm{dFe}],[\mathrm{dFe}]$ minima in the $40-150 \mathrm{~m}$ depth range and increase in concentration between $150 \mathrm{~m}$ and $500 \mathrm{~m}$ to concentrations around $0.4-0.6 \mathrm{nM}$. The spring [dFe] profiles of the two studies have generally weaker gradients and lower concentrations of $\mathrm{dFe}$ than the summer profiles.

This study is aimed at a better general understanding of iron biogeochemistry and the role of iron speciation in it, an aspect so far neglected in most models. One outcome of this work is the identification of parameters that need to be better constrained in order to improve the prediction of speciation, concentration and fluxes of iron in the world ocean. This study focusses on (i) the concentrations below the annual mixed layer and how they are affected by the parameterisation of loss processes that transfer dissolved iron to sinking particles either through scavenging or through a colloid intermediate; and (ii) the vertical scale of the fast redox cycling within the mixed layer. The model is primarily a tool to help in understanding the key processes of the iron cycle and their sensitivities to uncertainties in our present descriptions of these processes rather than as a numerically accurate reproduction of reality.

The paper is organised as follows: After a description of the model in Sect. 2, results of the physical and ecosystem model components are described briefly in Sects. 3 and 4. In Sect. 5 we deal with the difficulty to reconcile slow iron loss processes at depth with short timescales in the mixed layer. In Sect. 6 we discuss the modeled diurnal and annual dynamics of the iron-cycle, followed by a study about the model sensitivity to parameter changes in Sects. 7 and 8. We conclude in Sect. 9, summarising the main outcomes of this study.

\section{Model description}

The model used in this study is a one-dimensional (1D) extension of an earlier zero-dimensional (0D) model by Weber et al. (2005). It distinguishes between the following four dissolved iron species $(\mathrm{dFe})$ : dissolved inorganic ferric iron $\mathrm{Fe}(\mathrm{III})^{\prime}$ and ferrous iron $\mathrm{Fe}(\mathrm{II})^{\prime}$, organically complexed iron $\mathrm{FeL}$ and colloidal iron $\mathrm{Fe}_{\mathrm{col}}$, defined here by filter cutoffs $0.02-0.4 \mu \mathrm{m}$ as in Wu et al. (2001). Furthermore the model calculates the concentrations of iron bound to the surface of sinking particles $\mathrm{Fe}_{p}$, hydrogen peroxide $\left(\mathrm{H}_{2} \mathrm{O}_{2}\right)$ and superoxide $\left(\mathrm{O}_{2}^{-}\right)$as well as of sinking particles, both inorganic from dust deposition and organic from detritus. Most determinations of organic complexation of iron in seawater have shown an excess of truly dissolved organic ligands over total dissolved iron (e.g. Rue and Bruland, 1995; Van den Berg, 1995; Wu and Luther III, 1995; Witter and Luther III, 1998) but the sources and fate of these ligands remain largely unknown. To avoid the additional uncertainty brought into the model solution by assuming essentially unconstrained creation and destruction pathways and rates for organic ligands we assume a fixed concentration of free iron-binding organic ligands L, taken from the work by Cullen et al. (2006) to ensure an excess of ligands. Model solutions depend only weakly on the value of this excess. The processes converting iron between its different forms (see Fig. 3) are parameterised as in Weber et al. (2005), from which we adopted initial rate constants. The only exception is the photoreduction rate of colloidal iron $\left(k_{\mathrm{ph} 1}\right)$. Estimates of $k_{\mathrm{ph} 1}$ by Wells and Mayer (1991) and Barbeau and Moffett (1998) are much lower (between 0.12 and $0.43 \mathrm{~d}^{-1}$ ) than the value by Johnson et al. (1994) $\left(20.16 \mathrm{~d}^{-1}\right)$, used by Weber et al. (2005). The latter value was calculated from data obtained by Waite and Morel (1984) at pH 6.5. Johnson et al. (1994) assumed that this rate was the same at $\mathrm{pH} 8$, which is not a reasonable assumption (King et al., 1993; Moffet, 2001). Daily values of dust deposition were taken from the output of a global atmospheric dust transport model by Mahowald et al. (2003). 
Table 1. Parameters of the NPZD Model.

\begin{tabular}{llll}
\hline Parameter & Symbol & Unit & Value \\
\hline & Biology & & \\
\hline maximum growth rate & $\mu^{*}$ & $\mathrm{~d}^{-1}$ & 0.27 \\
phytoplankton mortality & $\gamma_{p}$ & $\mathrm{~d}^{-1}$ & 0.04 \\
initial slope P-I curve & $\alpha$ & $\mathrm{m}^{2} \mathrm{~W}^{-1} \mathrm{~d}^{-1}$ & 0.256 \\
nitrate half-saturation constant & $K_{\mathrm{N}}$ & $\mu \mathrm{M}$ & 0.7 \\
iron half-saturation constant & $K_{\mathrm{Fe}}$ & $\mathrm{nM}$ & 0.2 \\
phytoplankton aggregation rate & $\gamma_{p^{2}}$ & $\mu \mathrm{M}^{-1} \mathrm{~d}^{-1}$ & 0.025 \\
maximum grazing rate & $g$ & $\mathrm{~d}^{-1}$ & 1.575 \\
prey capture rate & $\epsilon$ & $\mu \mathrm{M}^{-1} \mathrm{~d}^{-1}$ & 1.6 \\
assimilation efficiency & $\gamma_{\mathrm{za}}$ & - & 0.925 \\
excretion & $\gamma_{\mathrm{zb}}$ & $\mathrm{d}^{-1}$ & 0.01 \\
quadratic mortality & $\gamma_{z^{2}}$ & $\mu \mathrm{M}^{-1} \mathrm{~d}^{-1}$ & 0.34 \\
detritus remineralisation & $\gamma_{d}$ & $\mathrm{~d}^{-1}$ & 0.048 \\
sinking velocity & $w_{s}$ & $\mathrm{~m} \mathrm{~d}^{-1}$ & 18 \\
coefficient for temperature function & $C_{\mathrm{ref}}$ & - & 1.066 \\
PAR:short-wave irradiance ratio & $f_{\mathrm{PAR}}$ & - & 0.43 \\
attenuation due to chlorophyll & $\kappa$ & $\left(\mathrm{mg} \mathrm{Chl}^{-1} \mathrm{~L} \mathrm{~m}^{-1}\right.$ & 0.03 \\
maximum Fe:N ratio in organic matter & $r_{\mathrm{Fe}: \mathrm{N}}$ & $\mathrm{nM} \mu \mathrm{M}^{-1}$ & $3.3 \times 10^{-2}$ \\
minimum Fe:N ratio in organic matter & $Q_{\mathrm{min}}$ & $\mathrm{nM} \mathrm{M} \mathrm{M}^{-1}$ & $6.6 \times 10^{-3}$ \\
mass:N ratio in organic matter & $r_{\mathrm{m}: \mathrm{N}}$ & $\mathrm{g} \mathrm{mol}^{-1}$ & 159 \\
\hline
\end{tabular}

The biological part of the model is the nitrogen-based ecosystem model by Oschlies and Schartau (2005) with four compartments, representing inorganic nitrogen $(\mathrm{N})$, phytoplankton (P), zooplankton (Z) and detritus (D). Schartau and Oschlies (2003) calibrated this ecosystem model in a onedimensional mode against observations at the Bermuda Atlantic Time-series Study site and two other sites in the North Atlantic (Table 1). In contrast to Weber et al. (2005), who assumed a uniform Fe:N ratio in phytoplankton, zooplankton and detritus, we allow for a decoupling between the cycling of $\mathrm{Fe}$ and $\mathrm{N}$ by reducing the uptake of iron under low concentrations of the $\mathrm{Fe}$ species taken up. This requires an explicit modelling of the Fe content in the ecosystem compartments, i.e. the addition of three further model equations (see Appendix). It is generally thought that phytoplankton is not iron-limited at the BATS site (Fung et al., 2000; Watson, 2001). To be independent of this assumption, we nevertheless implemented a dependency of phytoplankton growth on its internal Fe:N quota, following the approach of Droop (1983), i.e. $\mu \propto\left(Q-Q_{\min }\right) / Q_{\min }$, with $Q$ the cellular Fe:N ratio. Concerning colimitation by light, DIN and iron we follow the minimum approach, i.e. the final growth rate is the minimum of a light-, DIN- or Fe-limited growth rate.

The physical part of the model is the General Ocean Turbulence Model (GOTM: www.gotm.net and Burchard et al. (2006)). We choose GOTM because it uses state-of-theart turbulence closure models, which is a precondition for properly simulating vertical profiles of reactive biogeochemical quantities. For the present study, a two-equation $k-\varepsilon$ model with an algebraic second moment closure by Cheng et al. (2002) was chosen (see Umlauf and Burchard, 2005 for the consistent implementation of this scheme). Furthermore, GOTM provides stiff equation solvers appropriate for dealing with the very fast photochemical reaction rates in the model. In particular we used the recently developed non-negative and conservative modified Patankar-type solvers for ordinary differential equations (Burchard et al., 2005; Bruggeman et al., 2006). Meteorological data are derived from the ERA-40 reanalysis project (Uppala et al., 2005) to drive the physical model. Sea surface temperature and salinity were restored towards observations with a time-scale of 5 days.

We used the light extinction routine after Jerlov (1968); Paulson and Simpson (1977) provided by GOTM. Photosynthetically available radiation is assumed to be $43 \%$ of the total incoming irradiance (Brock, 1981). Ultraviolet radiation (UV) is not separately calculated although we are aware that it might also be important for the iron chemistry at the surface (Kuma et al., 1992; Rijkenberg et al., 2005). The transmission of light through the water column depends on optical water types and is prescribed by means of choosing a Jerlov (1968) class. According to Jerlov (1968) and by adjusting the parameter for attenuation due to chlorophyll and water, we choose the oceanic type IB, which gave model results for nutrient and chlorophyll $\alpha$ concentrations that are closest to observations (Sect. 4).

A time-step of $1 \mathrm{~min}$ was chosen for the integration. When used with GOTM's stiff equation solver, such a time-step is short enough to deal with the fast photochemical reaction 
rates. A total period of 9 years was integrated, covering the period from the beginning of 1988 until the end of 1997. The first two years were used for spin-up. The vertical grid consists of 100 layers over $600 \mathrm{~m}$, with layer thickness increasing non-linearly from $0.9 \mathrm{~m}$ in the upper layer to $12.45 \mathrm{~m}$ at $600 \mathrm{~m}$ depth. Sinking biogenic matter remineralises throughout the water column. The remainder that reaches the lowermost model box is instantaneously remineralised there. As we are considering here only the upper $250 \mathrm{~m}$ of the water column, this assumption does not affect model results within the timescale of the experiments.

\section{Results of the physical model}

The annual cycle of the physical properties in the model is driven primarily by seasonal changes in surface heat flux and wind stress. Strong thermal stratification is present in summer, largely due to higher heat fluxes and lower wind stresses. The modeled temperature and salinity profiles as well as the mixed layer depth are in good agreement with observations (Steinberg et al., 2001): In summer, the mixedlayer has temperatures around $25^{\circ} \mathrm{C}$, and is generally of reduced salinity. There is a subsurface salinity maximum, and strong density gradients in the upper $100 \mathrm{~m}$. Temperature fluctuation of the surface layer (top 1-2 m), associated with the diurnal thermal cycle, ranges from 0.2 to $2.5^{\circ} \mathrm{C}$ depending on the net daytime surface heat flux (controlled by cloud cover and wind stress) and mixed-layer depth. In winter, the mixed layer is more saline and mean temperatures are around $19^{\circ} \mathrm{C}$, while mixed-layer depths vary from 150 to $250 \mathrm{~m}$.

In summary, the GOTM results show a good fit to the observations at the BATS site, and meet the requirements of the present study.

\section{Results of the ecosystem model}

The ecosystem model has already been used to study the nitrogen cycle at the BATS site with good results (Oschlies and Schartau, 2005). However, this study used a different physical model and different forcing fields. We therefore briefly present here the main features of the biological model solution for a model run without Fe-limitation of growth. If iron limitation leads to changes in the biological solution in the model runs described in the following, this will be mentioned there.

The concentration of DIN in the surface mixed layer at the BATS site follows an annual cycle that is characterised by a peak in late winter, caused by the deepening of the mixed layer, followed by values below detection limit over summer, reflecting the oligotrophic conditions in the North Atlantic subtropical gyre. Below the depth of the winter mixed layer, DIN concentrations increase with depth. The model reproduces this DIN concentration pattern qualitatively well.
However, some quantitative differences between observations and model results remain: Modeled surface DIN concentrations remain around $0.2 \mu \mathrm{M}$ during summer, while observations show values below the detection limit. The discrepancy is on the order of magnitude of the DIN detection limit of conventional nutrient measurement techniques, but may nevertheless indicate a deficiency of the model, e.g. the neglection of picoplankton. Peak winter concentrations are generally higher in the model (typically $1 \mu \mathrm{M}$ ) than in the data (typically $0.6 \mu \mathrm{M}$ ). Also the model shows some trend towards increasing DIN around $250 \mathrm{~m}$ depth, indicating that equilibrium has not been reached completely.

The distribution of $\mathrm{Chl} \alpha$ at the BATS site is characterised by a spring bloom that is initiated by the increasing irradiance during the annual shoaling of the mixed layer, and later by the development of a deep chlorophyll maximum below the shallow summer mixed layer. The modeled timing of the spring bloom is in good agreement with observations. During late spring and summer the modeled concentrations reveal a deep $\mathrm{Chl} \alpha$ maximum similar to observations. Chl $\alpha$ concentrations are slightly overestimated in the model, especially in the upper $60 \mathrm{~m}$ (around $0.1 \mu \mathrm{gl}^{-1}$ ) Lower concentrations in Chl $\alpha$ were observed in years 1990-1991 which are not reproduced by the model.

The annually averaged vertical sinking flux of detritus at $100 \mathrm{~m}$ depth varies between 0.41 and $0.69 \mathrm{~mol} \mathrm{C} \mathrm{m}^{-2} \mathrm{a}^{-1}$. Taking into account also the vertical diffusion of particulate organic nitrogen $(\mathrm{PON}=\mathrm{P}+\mathrm{Z}+\mathrm{D})$ we get annually averaged vertical fluxes varying between 0.75 and $1.36 \mathrm{~mol} \mathrm{C} \mathrm{m}^{-2} \mathrm{a}^{-1}$. This is within the range of published estimates of export production at the BATS site (0.7 to $4.4 \mathrm{~mol} \mathrm{C} \mathrm{m}^{-2} \mathrm{a}^{-1}$, depending on the method used, Carlson et al. (1994)), albeit at the lower end. Both the assumption of a constant $\mathrm{C}: \mathrm{N}$ ratio of 6.625 in organic matter and the lack of a dissolved organic carbon pool might underestimate the export production of the model.

The ecosystem model results show some deficiencies, such as an overestimation of summer concentrations of dissolved inorganic nitrogen and chlorophyll, which are, however, not uncommon for this type of ecosystem studies, especially without using data-assimilation methods. For the purpose of this study, however, it is mainly the modeled vertical export flux and the magnitude and timing of primary production, which are important. These quantities are in agreement with observations within the observational scatter. Model solutions for $\mathrm{P}_{\mathrm{Fe}}, \mathrm{Z}_{\mathrm{Fe}}$ and $\mathrm{D}_{\mathrm{Fe}}$, i.e. the iron content in the ecosystem model, depend on the dissolved iron concentrations in the water column and will be discussed in the following sections. 

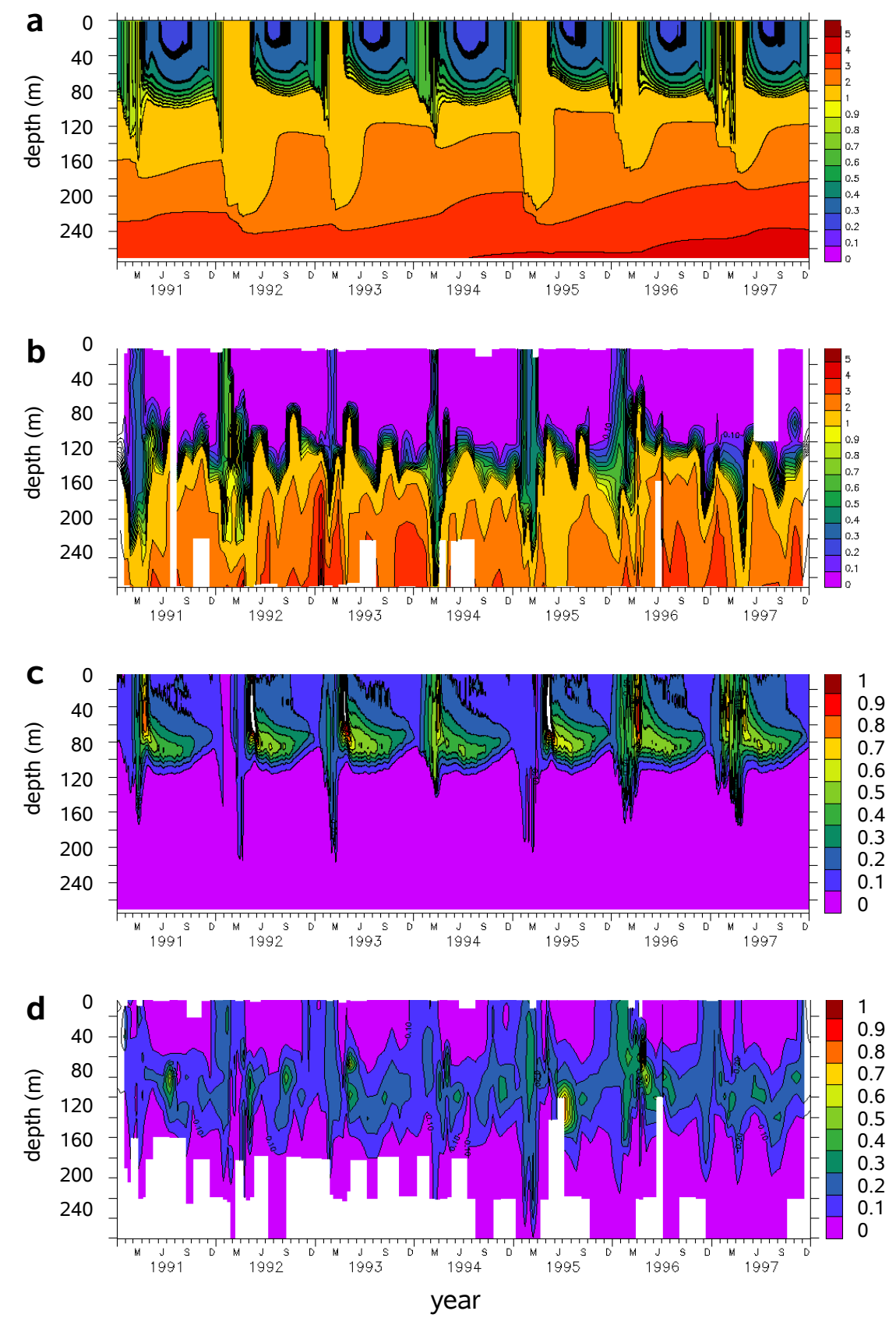

Fig. 1. Modeled $(\mathrm{a}+\mathrm{c})$ and observed $(\mathrm{b}+\mathrm{d})$ concentrations of DIN (Nitrate + Nitrite) in $\mu \mathrm{M}(\mathrm{a}+\mathrm{b})$ and chlorophyll $\alpha$ in $\mu \mathrm{g} \mathrm{l}^{-1}(\mathrm{c}+\mathrm{d})$. Observed values were taken from BATS bottle observations and linearly interpolated in the vertical.

\section{Iron fluxes below the mixed layer}

\subsection{Initial state}

For the initial model run of the present study (Run I), the same parameter set for the iron chemistry is used as in the zero-dimensional model of Weber et al. (2005) (Table 2; apart from the photoreduction rate of colloidal iron as dis- cussed above). This setting generates results incompatible with observations in several aspects: Modeled dissolved iron concentrations within the mixed layer after the first 5 model years vary between 0.3 to $0.4 \mathrm{nM}$ in summer and below $0.2 \mathrm{nM}$ in spring. Because of the low $[\mathrm{dFe}]$ values in the mixed layer, uptake of iron by phytoplankton is strongly limited, leading to Fe:N quotas in the ecosystem model below $1 / 3$ of the maximum. This leads to a strong suppression 
Table 2. Parameters of the chemical model from the zero-dimensional model by Weber et al. (2005) (Run I) and changed parameters in the one-dimensional model of the present study (Run A).

\begin{tabular}{|c|c|c|c|c|}
\hline Parameter & Symbol & Unit & Run I & Run A \\
\hline \multicolumn{5}{|c|}{ Chemistry } \\
\hline $\mathrm{Fe}(\mathrm{II})^{\prime}$ oxidation rate by $\mathrm{O}_{2}$ & $k_{\mathrm{Ox} 1}$ & $\mu \mathrm{M}^{-1} \mathrm{~d}^{-1}$ & 0.864 & - \\
\hline oxygen concentration & {$\left[\mathrm{O}_{2}\right]$} & $\mu \mathrm{M}$ & 214 & - \\
\hline $\mathrm{Fe}(\mathrm{III})^{\prime}$ oxidation rate by $\mathrm{O}_{2}^{-}$ & $k_{\mathrm{ox} 2}$ & $\mathrm{nM}^{-1} \mathrm{~d}^{-1}$ & 864 & - \\
\hline $\mathrm{Fe}(\mathrm{II})^{\prime}$ oxidation rate by $\mathrm{H}_{2} \mathrm{O}_{2}$ & $k_{0 \times 3}$ & $\mathrm{nM}^{-1} \mathrm{~d}^{-1}$ & 6.24 & - \\
\hline $\mathrm{Fe}_{\mathrm{col}}$ photoreduction rate at $30 \mu \mathrm{E} \mathrm{m}^{-3} \mathrm{~s}^{-1}$ & $k_{\mathrm{ph} 1}$ & $d^{-1}$ & 20.16 & 0.432 \\
\hline FeL photoreduction rate at $30 \mu \mathrm{E} \mathrm{m}^{-3} \mathrm{~s}^{-1}$ & $k_{\mathrm{ph} 2}$ & $d^{-1}$ & 86.4 & - \\
\hline $\mathrm{Fe}(\mathrm{III})^{\prime}$ photoreduction rate at $30 \mu \mathrm{E} \mathrm{m}^{-3} \mathrm{~s}^{-1}$ & $k_{\mathrm{ph} 3}$ & $d^{-1}$ & 1.32 & - \\
\hline $\mathrm{Fe}_{p}$ photoreduction rate at $30 \mu \mathrm{E} \mathrm{m}^{-3} \mathrm{~s}^{-1}$ & $k_{\mathrm{ph} 4}$ & $d^{-1}$ & 20.2 & - \\
\hline $\mathrm{Fe}_{\mathrm{col}}$ formation rate & $k_{\mathrm{col}}$ & $\mathrm{d}^{-1}$ & 2.4 & - \\
\hline FeL formation rate & $k_{\mathrm{fel}}$ & $\mathrm{nM}^{-1} \mathrm{~d}^{-1}$ & 172.8 & - \\
\hline FeL conditional stability constant & $k_{\mathrm{ld}}$ & $\mathrm{M}^{-1}$ & $10^{20.3}$ & $10^{22}$ \\
\hline free organic ligand concentration & {$[\mathrm{Lig}]$} & $\mathrm{nM}$ & - & 2.4 \\
\hline $\mathrm{Fe}(\mathrm{IIII})^{\prime}$ reduction rate by $\mathrm{O}_{2}^{-}$ & $k_{\text {red }}$ & $\mathrm{nM}^{-1} \mathrm{~d}^{-1}$ & $1.3 \times 10^{4}$ & - \\
\hline $\mathrm{Fe}(\mathrm{III})^{\prime}$ scavenging rate & $k_{\mathrm{sca}}$ & $\mathrm{kg}^{-1} 1 \mathrm{~d}^{-1}$ & $2.5 \times 10^{4}$ & - \\
\hline $\mathrm{Fe}_{\mathrm{col}}$ aggregation rate & $k_{\mathrm{ag}}$ & $\mathrm{kg}^{-1} 1 \mathrm{~d}^{-1}$ & $1.224 \times 10^{6}$ & $1.224 \times 10^{5}$ \\
\hline $\mathrm{O}_{2}^{-}$dismutation rate & $k_{\mathrm{dm}}$ & $\mathrm{nM}^{-1} \mathrm{~d}^{-1}$ & 2.64 & - \\
\hline $\mathrm{O}_{2}^{-}$production rate at $30 \mu \mathrm{E} \mathrm{m}^{-3} \mathrm{~s}^{-1}$ & $S_{\mathrm{O}_{2}^{-}}$ & $\mathrm{nM} \mathrm{d}^{-1}$ & 1037 & - \\
\hline $\mathrm{H}_{2} \mathrm{O}_{2}$ decay rate & $k_{\mathrm{dis}}^{2}$ & $d^{-1}$ & 0.24 & - \\
\hline solubility of atmospheric iron & $k_{\mathrm{sol}}$ & $\%$ & 1 & - \\
\hline Total $\mathrm{Cu}$ concentration & {$\left[\mathrm{Cu}_{\mathrm{T}}\right]$} & $\mathrm{nM}$ & 1 & - \\
\hline $\mathrm{Cu}(\mathrm{I})$ oxidation rate by $\mathrm{O}_{2}^{-}$ & $\mathrm{k}_{\text {cuox }}$ & $\mathrm{nM}^{-1} \mathrm{~d}^{-1}$ & $8.1 \times 10^{5}$ & - \\
\hline $\mathrm{Cu}$ (II) reduction rate by $\mathrm{O}_{2}^{-}$ & $\mathrm{k}_{\text {cured }}$ & $\mathrm{nM}^{-1} \mathrm{~d}^{-1}$ & $1.4 \times 10^{3}$ & - \\
\hline
\end{tabular}

of phytoplankton growth during spring and early summer, through the dependency of phytoplankton growth on the internal Fe:N quota, and in consequence to summer DIN concentrations of more than $2 \mu \mathrm{M}$. Instead of the observed spring phytoplankton bloom we obtain a late summer bloom triggered by dust deposition.

Below the mixed layer, dissolved iron concentrations are lower than $0.2 \mathrm{nM}$ and still continue to decrease slightly at the end of the integration period, independent of the chosen bottom boundary condition. In contrast, observations at the BATS site show annual variations between $0.1 \mathrm{nM}$ and $2.0 \mathrm{nM}$ at the surface, a subsurface minimum around $0.1 \mathrm{nM}$ near $100 \mathrm{~m}$ depth, and values between $0.4-0.6 \mathrm{nM}$ below ( $\mathrm{Wu}$ and Boyle, 2002; Sedwick et al., 2005).

The main difference to the 0-dimensional model, where the same parameter set had produced results in accordance with observations (Weber et al., 2005), is that in the 1Dapproach the concentration of dissolved Fe below the surface mixed layer is generated by the model itself instead of being prescribed. This indicates that either the sources of iron at depth from remineralisation or physical transport are underestimated or that the modeled iron sinks from scavenging and aggregation at depth are overestimated in the current model setting.
The modeled physical transport of dissolved iron is unlikely to be a major model deficiency: Vertical diffusion is rather low in the model $\left(<1 \mathrm{~cm}^{2} \mathrm{~s}^{-1}\right)$, in agreement with observational estimates by Musgrave et al. (1988) and Ono et al. (2001). Lateral advection, which is neglected in a 1dimensional model, could be a missing source of iron in the model. However, given the small current velocities (McClain and Firestone, 1993), this would require large horizontal $[\mathrm{dFe}]$ gradients at depth.

The main problem in this model setting occurs to be the loss of dissolved iron through formation and aggregation of colloids and scavenging.

\subsection{Adjustment of the residence time at depth}

The concentration of iron (in its different forms) below the mixed layer must adapt itself in the long-term average such that the source of dissolved iron, which is predominantly the remineralisation of organic matter, equals the loss through transfer of dissolved forms of iron to to the particulate pool by scavenging and colloid aggregation. That this balance results in iron concentrations that are lower than observations can therefore have three explanations: (i) the assumed rates for colloidal aggregation and/or scavenging are too large and/or (ii) organic complexation processes, which increase 
the residence time of iron, are too weak and/or (iii) the modeled sources of iron are too small. Point (iii) will be discussed in Sects. 7 and 8.

A qualitative understanding of (i) and (ii) can be obtained from a simplified calculation: If we neglect photochemistry, vertical transport and temporal variability, we obtain the following three balances for dissolved iron species:

- colloid formation equals aggregation loss,

$$
k_{c}\left[\mathrm{Fe}(\mathrm{III})^{\prime}\right]=k_{a}\left[\mathrm{Fe}_{\mathrm{col}}\right]
$$

where $k_{a}=k_{\mathrm{ag}}\left([A]+r_{\mathrm{m}: \mathrm{N}}[D]\right)$ is the effective aggregation rate.

- dissociation of organic iron complexes equals formation of organic iron complexes plus scavenging and colloid formation,

$$
\begin{aligned}
k_{l d}[\mathrm{FeL}]= & k_{\mathrm{fel}}\left[\mathrm{Fe}(\mathrm{III})^{\prime}\right][\mathrm{L}]+k_{s}\left[\mathrm{Fe}(\mathrm{III})^{\prime}\right] \\
& +k_{c}\left[\mathrm{Fe}(\mathrm{III})^{\prime}\right]
\end{aligned}
$$

where $k_{s}=k_{\mathrm{sca}}\left([A]+r_{\mathrm{m}: \mathrm{N}}[D]\right)$ is the effective scavenging rate (note that both scavenging and aggregation in reality depend on particle surface rather than mass. To keep the model simple, we assume that the two are proportional, i.e. that the particle size spectrum is invariant).

- remineralisation of iron from decay of organic matter equals complex dissociation minus complex formation,

$$
R=k_{\mathrm{ld}}[\mathrm{FeL}]-k_{\mathrm{fel}}\left[\mathrm{Fe}(\mathrm{III})^{\prime}\right][\mathrm{L}]
$$

where $R$ is the rate of iron release from remineralisation of organic matter $R=\gamma_{d} \mathrm{DFe}$.

From these balances we obtain

$$
\begin{aligned}
{\left[\mathrm{Fe}(\mathrm{III})^{\prime}\right] } & =\frac{R}{k_{c}+k_{s}} \\
{\left[\mathrm{Fe}_{\mathrm{col}}\right] } & =\frac{k_{c}}{k_{a}} \frac{R}{k_{c}+k_{s}} \\
{[\mathrm{FeL}] } & =\frac{R+k_{\mathrm{fel}}\left[\mathrm{Fe}(\mathrm{III})^{\prime}\right][\mathrm{L}]}{k_{\mathrm{ld}}}
\end{aligned}
$$

These expressions can be considerably simplified if we take into account that at typical particle concentrations in the model, the effective scavenging rate is much smaller than the colloid formation rate $k_{s}<k_{c}$, and that iron remineralisation is a much slower process than ligand formation $R<k_{\mathrm{fel}}\left[\mathrm{Fe}(\mathrm{III})^{\prime}\right][\mathrm{L}]$. To first order therefore $\left[\mathrm{Fe}(\mathrm{III})^{\prime}\right]=R / k_{c},\left[\mathrm{Fe}_{\mathrm{col}}\right]=R / k_{a}$, and $[\mathrm{FeL}] /\left[\mathrm{Fe}(\mathrm{III})^{\prime}\right]=[\mathrm{L}] k_{\mathrm{fel}} / k_{\mathrm{ld}}$, i.e. the inorganic iron concentration is inversely proportional to the colloid formation rate, the colloidal iron concentration is inversely proportional to the colloid aggregation rate, and the ratio of organically complexed iron to inorganic iron is proportional to the ligand stability constant $k_{\mathrm{fel}} / k_{\mathrm{ld}}$ and the ligand excess. These relations are valid only approximately, because of the neglection of diffusion and temporal covariances.

Nevertheless, it is obvious from Eq. (4) to (6) that the only way to bring $\left[\mathrm{Fe}_{\mathrm{col}}\right]$ into better agreement with observations is to decrease the colloid aggregation rate $k_{\mathrm{ag}}$. [FeL] can be increased by either increasing the ligand strength (i.e. decreasing $k_{\mathrm{ld}}$ ) or by increasing [Fe(III)'] through decreasing $k_{c}$, or by a combination of both. These qualitative considerations results in parameters modified (Run A) accordingly to $k_{\mathrm{ag}}=1.224 \times 10^{5}$ and $k_{\mathrm{ld}}=10^{22}$ (see Table 2). Results of the $1 \mathrm{D}$-model with this set of parameters are close to observations and will be discussed in more detail in Sect. 6. Run A will be referred as the standard model run of the present study.

\subsection{Comparison of parameters to data-based estimates}

In spite of low particle concentrations in the open ocean it is suggested that marine colloids are very dynamic with high colloidal aggregation rates (Moran and Buesseler, 1992; Baskaran et al., 1992). So far, there are no methods to measure colloids directly in situ in seawater at typical oceanic concentrations. Detailed processes that lead to changes in particle size distribution are not fully understood (Wells, 2002). This makes it difficult to represent colloidal processes in a model adequately. Weber et al. (2005) estimated the rate for colloid aggregation using radiotracer experiments by Wen et al. (1997), and assuming proportionality of the rate to both the concentration of particles and colloids. The experiments by Wen et al. (1997), however, were performed using relatively particle-rich waters from Galveston Bay and the Gulf of Mexico. For the particle-poor waters at the BATS site (around $0.01 \mathrm{mg} / \mathrm{L}$ ), a 10-fold lower aggregation appears to be possible. The rate constant for the formation of colloidal iron, $k_{c}$, appears to be somewhat better constrained, e.g. by Johnson et al. (1994) who determined $k_{c}$ by measuring the change in dissolved $\mathrm{Fe}(\mathrm{III})$ concentrations during dark periods from an initial concentration of $10 \mathrm{nM}$ Fe(III).

Weber et al. (2005) used a conditional stability constant of Fe-organic complexes of $10^{20.3} \mathrm{M}^{-1}$ from Wu and Luther III (1995). However, measured conditional stability constants for iron complexes in the ocean vary between $10^{18} \mathrm{M}^{-1}$ to $10^{22.5} \mathrm{M}^{-1}$ (e.g. Gledhill and van den Berg, 1994; Wu and Luther III, 1995; Van den Berg, 1995; Cullen et al., 2006) and often two ligands classes with different strengths are found (Gledhill and van den Berg, 1994; Rue and Bruland, 1995; Cullen et al., 2006) at one site. Our model presently allows only for one "typical" class. The value $10^{22} \mathrm{M}^{-1}$ that we use here agrees with the observed value for the stronger iron binding ligand in the Sargasso Sea by Cullen et al. (2006). The measurements by Cullen et al. (2006) suggest that the stronger ligand class dominates in the surface ocean, while 


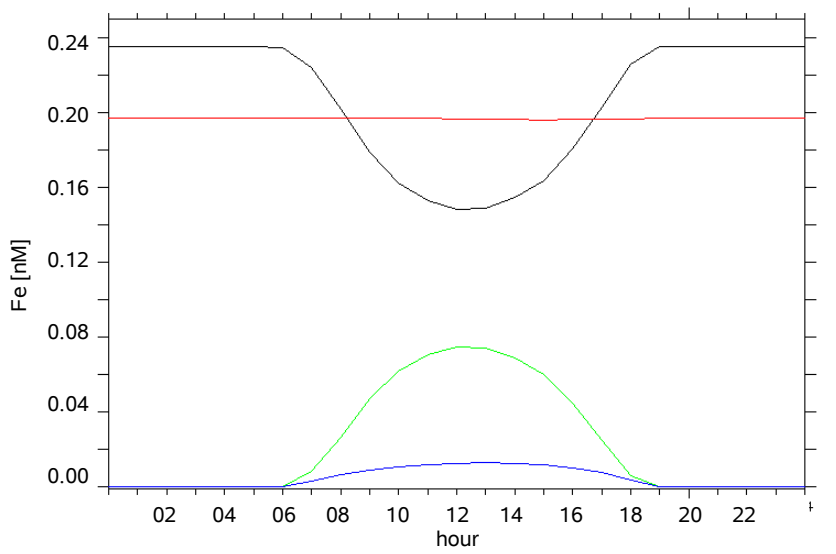

Fig. 2. Diurnal variability of modeled iron concentrations in $\mathrm{nM}$ for a typical summer day (02.08.1994), averaged over $40 \mathrm{~m}$ depth. The figures show FeL (black), $\mathrm{Fe}_{\mathrm{col}}$ (red), $\mathrm{Fe}(\mathrm{II})^{\prime}$ (green) and $\mathrm{Fe}(\mathrm{III})^{\prime}$ (blue).

the dominant ligand in deep waters has a stability constant 12-15 times smaller. In our model however, a stronger ligand with stability constant of around $10^{22}$ is required below the mixed layer to reproduce the profile of iron speciation by $\mathrm{Wu}$ et al. (2001). We realize that further model development in terms of different ligand classes is required. Since this will add new parameters to the model, such an approach will also need further information (qualitatively and quantitatively) from laboratory and field experiments with regard to the origin, strength and fate of organic ligands for iron in the seawater.

\section{Temporal dynamics in the mixed layer}

\subsection{Diurnal variability of iron speciation}

The modeled iron and reactive oxygen speciation in run A shows a strong diurnal variablity in the upper water column (Fig. 2), similar to the results of the zero-dimensional model by Weber et al. (2005).

The modeled hydrogen peroxide $\left(\mathrm{H}_{2} \mathrm{O}_{2}\right)$ concentrations follow a distinct diurnal pattern, with highest values during mid to late afternoon and lowest concentrations in the morning. The depth limit of diurnal variations in $\mathrm{H}_{2} \mathrm{O}_{2}$ concentration is variable, ranging most time of the year around 50 to $60 \mathrm{~m}$ depth. Over the annual cycle, the modeled mixedlayer averaged concentration of $\mathrm{H}_{2} \mathrm{O}_{2}$ varies between $32 \mathrm{nM}$ in winter and around $72 \mathrm{nM}$ in summer. These results are in good agreement with observations in the subtropical Atlantic by Obernosterer et al. (2001). They detected $\mathrm{H}_{2} \mathrm{O}_{2}$ concentrations of, on average, $42 \mathrm{nM}$ in both surface waters and in profiles up to $50 \mathrm{~m}$ depth. This followed a distinct diurnal pattern with highest concentrations during mid to late afternoon and lowest concentrations during the morning. The
Table 3. Maximum redox rates in $\mathrm{nMd}^{-1}$ at noon in August

\begin{tabular}{cccc}
\hline Rate & 1 m depth & 40 m depth & 100 m depth \\
\hline$k_{\text {ox } 1}$ & 34.70 & 4.33 & 0.16 \\
$k_{\text {ox2 }}$ & 317.50 & 6.98 & 0.02 \\
$k_{\text {ox3 }}$ & 245.80 & 9.40 & 0.02 \\
$k_{\text {red }}$ & 589.60 & 18.95 & 0.10 \\
$k_{\text {ph1 }}$ & 0.22 & 0.01 & 0.00 \\
$k_{\mathrm{ph} 2}$ & 20.42 & 2.16 & 0.14 \\
$k_{\mathrm{ph} 3}$ & 0.08 & 0.00 & 0.00 \\
$k_{\mathrm{ph} 4}$ & 0.00 & 0.00 & 0.00 \\
\hline
\end{tabular}

lifetime of superoxide is extremely short (order of seconds) so that its modeled concentration correlates strongly to irradiance with maximum values at noon and absence of $\mathrm{O}_{2}^{-}$at nighttime.

$\mathrm{FeL}$ and $\mathrm{Fe}_{\mathrm{col}}$ are the dominant forms of iron during the night. During daytime the concentrations of $\mathrm{Fe}(\mathrm{II})^{\prime}, \mathrm{Fe}(\mathrm{III})^{\prime}$ become significant due to photochemical reactions. Fe(II) ${ }^{\prime}$ is produced by direct photoreduction of ferric iron species and by the reduction of $\mathrm{Fe}(\mathrm{III})^{\prime}$ by photoreduced superoxide (Table 3). Consistent with the rates estimated by Voelker and Sedlak (1995), iron reduction by superoxide occurs at a rate that is up to more than a hundred times the maximum rate of all direct photoreductive processes taken together. Photoproduction of superoxide and its subsequent transformation to hydrogen peroxide leads to a corresponding cycle of iron redox-reactions and to an increase in $\left[\mathrm{Fe}(\mathrm{II})^{\prime}\right]$ and $\left[\mathrm{Fe}(\mathrm{IIII})^{\prime}\right]$ in the daytime at the expense of $[\mathrm{FeL}]$. Variation in $[\mathrm{FeL}]$ between day and night is up to $60 \%$ at the surface. The $\mathrm{Fe}(\mathrm{II})^{\prime}$ produced is subsequently oxidised again to $\mathrm{Fe}(\mathrm{III})^{\prime}$ by $\mathrm{O}_{2}, \mathrm{O}_{2}^{-}$and $\mathrm{H}_{2} \mathrm{O}_{2}$. Until midday, iron reduction outweighs oxidation, leading to an increase of $\left[\mathrm{Fe}(\mathrm{II})^{\prime}\right]$, but also of $\left[\mathrm{Fe}(\mathrm{III})^{\prime}\right]$ at the expense of $[\mathrm{FeL}]$. In the afternoon, the balance between reduction and oxidation is reversed because $\left[\mathrm{H}_{2} \mathrm{O}_{2}\right]$ reaches its maximum, and $\left[\mathrm{Fe}(\mathrm{II})^{\prime}\right]$ decreases. During the night all photochemical reactions stop so that all $\mathrm{Fe}(\mathrm{II})^{\prime}$ is oxidised to $\mathrm{Fe}(\mathrm{III})^{\prime}$, some of which is rapidly complexed by free organic ligands. The formation and photoreduction of colloidal iron in the model is a much slower process (one to two order of magnitudes) compared to organic complexation, oxidation and photoreduction (Fig. 3). Variations in $\left[\mathrm{Fe}_{\mathrm{col}}\right]$ between day and night are therefore only a few percent (around 1\% at the surface).

Light, the driving force behind photochemical cycling, decreases strongly with depth. Compared to the surface, modeled photoreduction and oxidation rates are about one order of magnitude lower at $40 \mathrm{~m}$ depth and about four orders of magnitude lower at $100 \mathrm{~m}$ depth (Table 3). On the other hand, the strong vertical mixing within the mixed layer acts to oppose the creation of concentration gradients within the mixed layer. The vertical distribution of (directly or indirectly) photoproduced species, such as $\mathrm{Fe}(\mathrm{II})^{\prime}$ therefore 


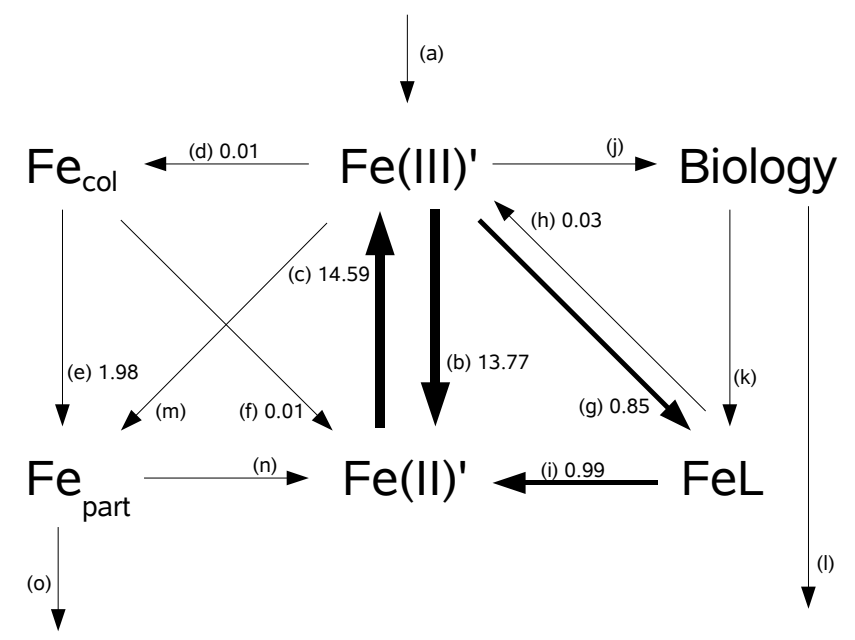

Fig. 3. Schematic representation of the iron pools represented in the model and the fluxes between them and their annually averaged rates of change of modeled iron concentrations $\left[\mathrm{nM} \mathrm{d}^{-1}\right]$ in $0-40 \mathrm{~m}$ depth. Arrows without number are smaller than 0.01 . The fluxes are not balanced because of the missing vertical fluxes in this figure. (a) dust deposition, (b) reduction by light and $\mathrm{O}_{2}^{-}$, (c) oxidation by $\mathrm{O}_{2}, \mathrm{O}_{2}^{-}$and $\mathrm{H}_{2} \mathrm{O}_{2}$, (d) formation of colloids, (e) aggregation, (f) photoreduction, (g) FeL formation, (h) FeL dissociation, (i) photoreduction, (j) biological uptake, (k) remineralisation, (l) sinking, (m) adsorption, (n) photoreduction, (o) sinking.

depends on the equilibrium between mixing and production which is strongly affected by the life-time of the species. The shorter the life-time of a species is, compared to the time-scale of vertical mixing, the stronger its vertical distribution is coupled to that of its production (Doney et al., 1995). Model results clearly show strong vertical gradients in the amplitude of the diurnal cycle of all photoproduced species (superoxide, $\mathrm{Fe}(\mathrm{II})^{\prime}, \mathrm{Fe}(\mathrm{III})^{\prime}$ and hydrogen peroxide) within the mixed layer. The different life-times of the different photochemically produced species are reflected in different depth dependencies of their daily cycle (Fig. 4).

The concentration of the shortest-lived species, superoxide, decreases strongest with depth, while the daily cycle of hydrogen peroxide is less directly related to the exponential decrease of light intensity. The creation of vertical gradients within the mixed layer is enhanced by the stabilisation of the water column during the day by solar warming. The redox-reactions of inorganic $\mathrm{Fe}$ and organic complexation determine the residence time of dissolved iron in the euphotic zone by keeping iron in solution (Fe(II) ${ }^{\prime}, \mathrm{Fe}(\mathrm{III})^{\prime}$ and $\mathrm{FeL}$ ) and therefore preventing it from scavenging or building colloids and subsequently aggregating.

Therefore, a distinct profile of [ $\mathrm{dFe}]$ develops with higher concentrations of iron at the surface, strongly decreasing then over the upper $50 \mathrm{~m}$ with decreasing light availability. Additional to the decrease in photochemical activity with depth,

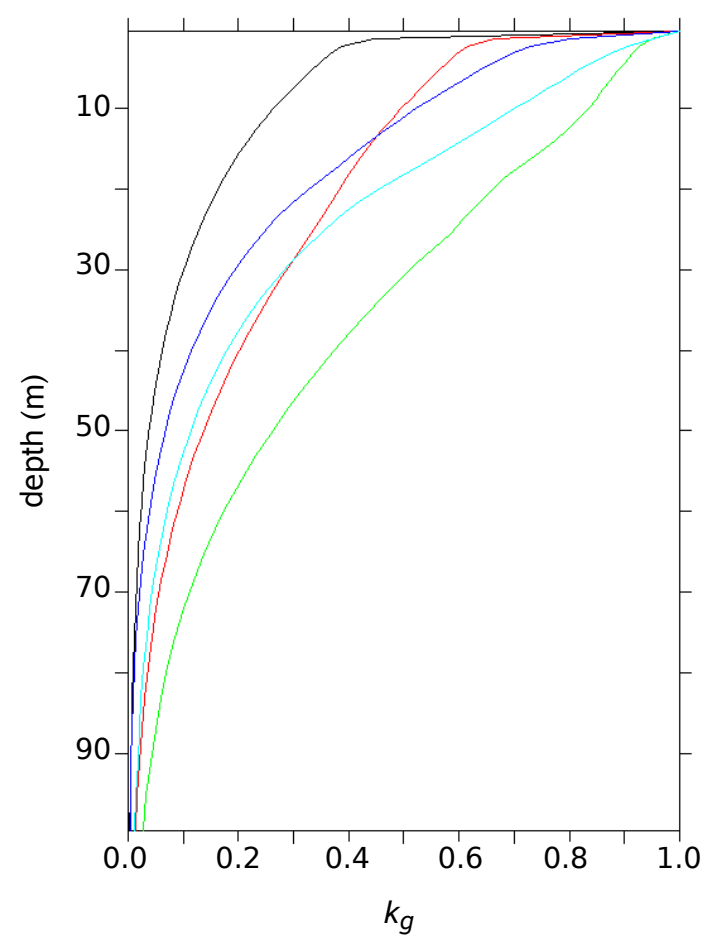

Fig. 4. Concentration difference (noon minus midnight) for several phochemically influenced species (red: $\mathrm{O}_{2}^{-}$, blue: $\mathrm{Fe}(\mathrm{II})^{\prime}$, magenta: $\mathrm{Fe}(\mathrm{III})^{\prime}$, green: $\mathrm{H}_{2} \mathrm{O}_{2}$ ) and downwelling irradiation (black) as a function of depth. All concentration differences have been scaled to one at the surface to make the different vertical scales visible. Average for the period 1 June-31 August.

a [dFe] minimum develops between 50 and $100 \mathrm{~m}$ due to increased biological activity at this depth (Sect. 4). Right below the deep chlorophyll maximum $[\mathrm{dFe}]$ increases slightly (about $0.02 \mathrm{nM}$ ) due to remineralisation of organic detritus but decreases considerably with depth below $125 \mathrm{~m}$.

The model results agree well in summer with observations by Wu and Luther III (1994) (Fig. 5). A similar vertical pattern is also observed by Sedwick et al. (2005) but with a greater range between maximum and minimum concentrations of the profile. The iron profile concentrations in spring are similar to the observations by $\mathrm{Wu}$ and Boyle (1998), with smaller differences between minimum and maximum concentrations in spring than in summer. Below $200 \mathrm{~m}$ modelled [dFe] is slightly lower (about $0.15 \mathrm{nM}$ ) than observations by Wu and Boyle (1998); Sedwick et al. (2005).

6.2 Annual cycle and interannual variability of dissolved iron

The modeled concentration of dissolved iron in the mixed layer ranges from $0.35 \mathrm{nM}$ in spring to $0.75 \mathrm{nM}$ in summer (Fig. 6), which is within the range of observations by $\mathrm{Wu}$ and Boyle (2002) (0.2-0.6 nM) and by Sedwick et al. (2005) 


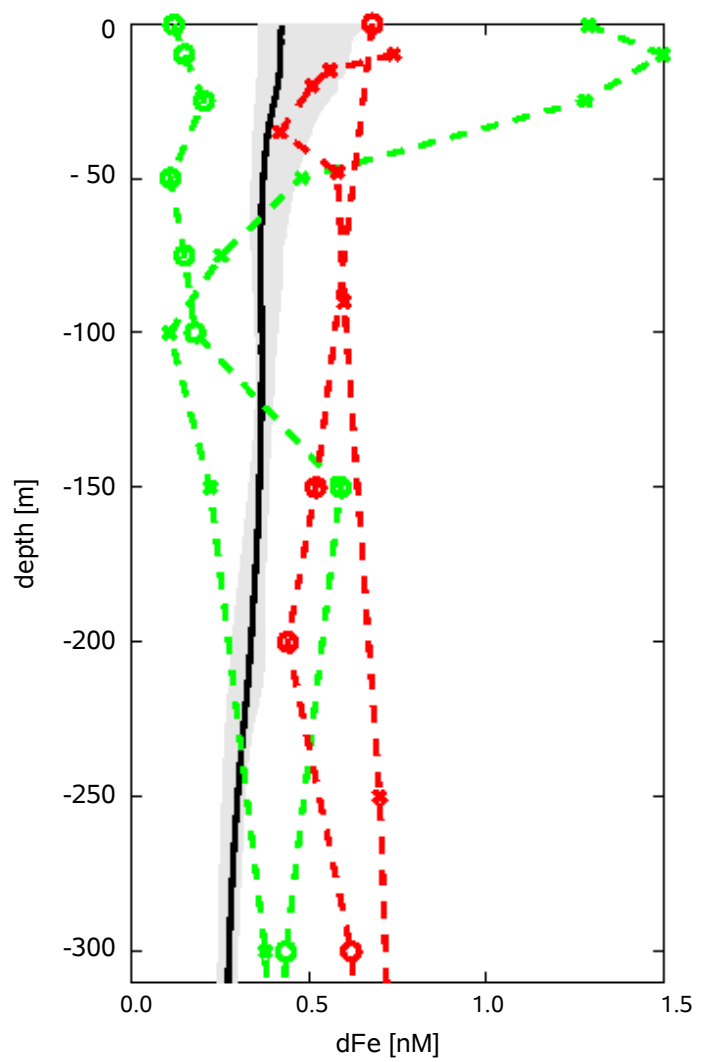

Fig. 5. Annual mean profile of modeled dFe concentration (black line) with maximum (summer) and minimum (spring) values (area in light gray). Measured dFe concentration at BATS in spring (circle) and summer (cross) by Wu and Luther III (1994); Wu and Boyle (1998) (red) and Sedwick et al. (2005) (green)

$(0.1-2 \mathrm{nM})$. These iron concentrations are never limiting for phytoplankton uptake. Therefore the Fe: $\mathrm{N}$ quota in phytoplankton, zooplankton and detritus are always close to the prescribed maximum quota $r_{\mathrm{Fe}: \mathrm{N}}$. The model seems to overestimate the minimum $\mathrm{dFe}$ concentrations, possibly because of the low value required for colloidal aggregation in the present model or a too low maximum $\mathrm{Fe}: \mathrm{N}$ ratio in phytoplankton (Wu and Boyle, 2002) (see also Sect. 8).

The range of iron concentration over the year is subject to a seasonal cycle of $[\mathrm{dFe}]$, caused by the annual mixed layer cycle, spring phytoplankton bloom and dust deposition.

Winter deepening of the mixed layer leads to dilution of [dFe]. Increased detritus concentrations in March and April, caused by the spring phytoplankton bloom, support colloidal aggregation and scavenging, which lead to a further drawdown in $[\mathrm{dFe}]$. Additionally, the uptake of iron by phytoplankton is increased at this time. The main import of iron occurs in summer when dust storms from the Sahara arrive. At this time the mixed layer is shallow and phytoplankton activity is low. The import of atmospheric iron increases [dFe] in the surface water until the winter deepening of the mixed layer starts again.
There is only little interannual variability in the annual cycle of $\mathrm{dFe}$ concentration and speciation. In contrast to that, dust deposition has a strong interannual variability, with changes by a factor of more than 2.5. Changes in iron input due to increased dust deposition are buffered in the model by a change in the residence time of $\mathrm{dFe}$ (Sect. 6.3) due to associated increase in particle concentration and therefore increased colloidal aggregation and scavenging.

\subsection{Residence time of iron}

The residence time of dissolved iron is usually defined as the ratio between the total dissolved iron concentration (in $\mathrm{nM}$ ) and the rate at which dissolved iron is lost (in $\mathrm{nM} \mathrm{d}^{-1}$ ). Typically, a constant scavenging residence time, i.e. a proportionality between dissolved iron concentration and scavenging loss is assumed. However, iron speciation, and nonlinearities in the dependency of loss on concentrations may make this assumption invalid. In the present model these processes are at least partially resolved. It is therefore interesting to investigate how the effective residence time in the model varies over time and depth, as we had to change the colloid aggregation rate in such a way that the model results are consistent with subsurface observations (Sect. 5.2).

We concentrate here on the residence time with respect to scavenging and colloid aggregation, i.e. the two processes that transfer iron from the colloidal and dissolved phase to filterable particles. This rate is formally defined by

$\tau=\frac{\left[\mathrm{Fe}(\mathrm{III})^{\prime}\right]+\left[\mathrm{Fe}(\mathrm{II})^{\prime}\right]+\left[\mathrm{Fe}_{\mathrm{col}}\right]+[\mathrm{FeL}]}{\left(k_{\mathrm{ag}}\left[\mathrm{Fe}_{\mathrm{col}}\right]+k_{\mathrm{sca}}\left[\mathrm{Fe}(\mathrm{III})^{\prime}\right]\right)\left([A]+r_{\mathrm{m}: \mathrm{N}}[D]\right)}$

where $[A]$ is the concentration of inorganic particles and $r_{\mathrm{m}: \mathrm{N}}[D]$ is the concentration of detritus in $\mathrm{kg} \mathrm{l}^{-1}$.

The scavenging residence time varies between about three years in late spring in $100 \mathrm{~m}$ depth, where the largest density of detritus occurs, and 1000 years in winter and at larger depths (Fig. 7). It is important to note that (a) this is the residence time to inorganic loss processes only, i.e. it does not include biological uptake, and (b) that at a specific depth it is probably the shortest residence time in the annual cycle that determines the effective loss rate. Below the upper $300 \mathrm{~m}, \tau$ approaches values of more than 100 years, consistent with data-based estimates of iron residence time (e.g. Johnson et al., 1997; Bergquist and Boyle, 2006).

The spatio-temporal pattern of $\tau$ primarily mirrors the distribution of detritus, with lowest values reached around $100 \mathrm{~m}$ depth just after phytoplankton blooms. Due to remineralisation, detritus concentrations decrease below this depth, leading to a corresponding increase in residence time. However, episodic dust deposition events also lead to reductions of $\tau$, primarily in summer. These are comparable in magnitude to spring bloom events but are typically only brief and progress through the whole water column without dispersion, as we have assumed a uniform particle sinking velocity. 


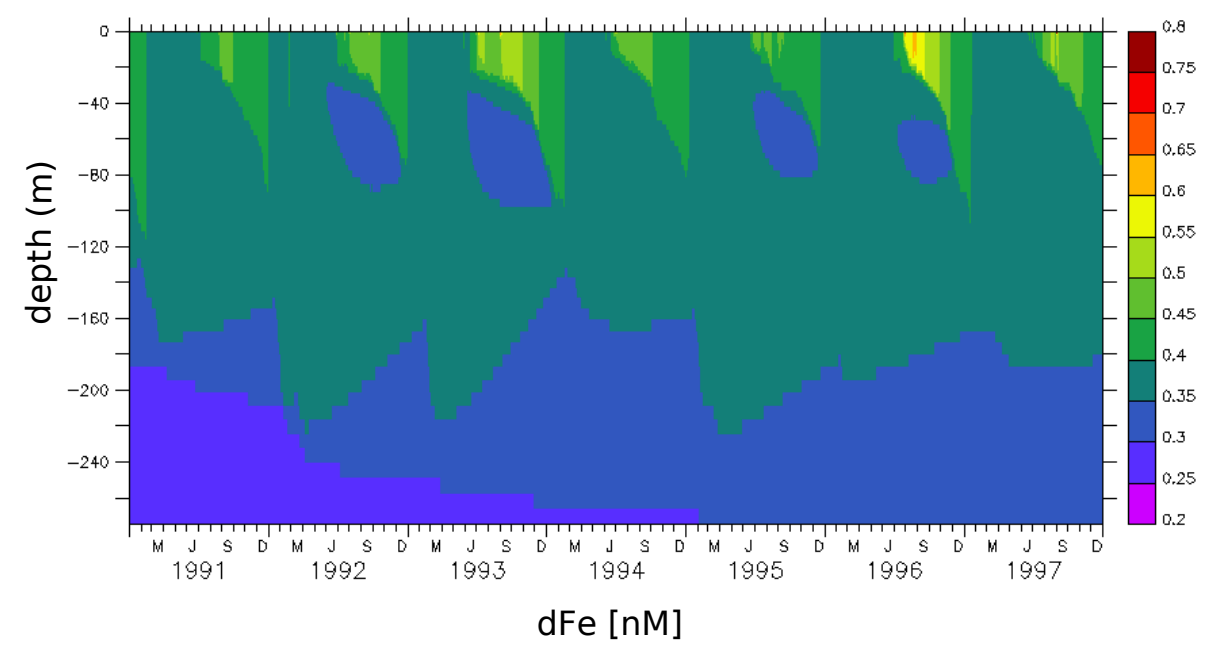

Fig. 6. Modeled concentrations of dFe in nM (Model Run A).
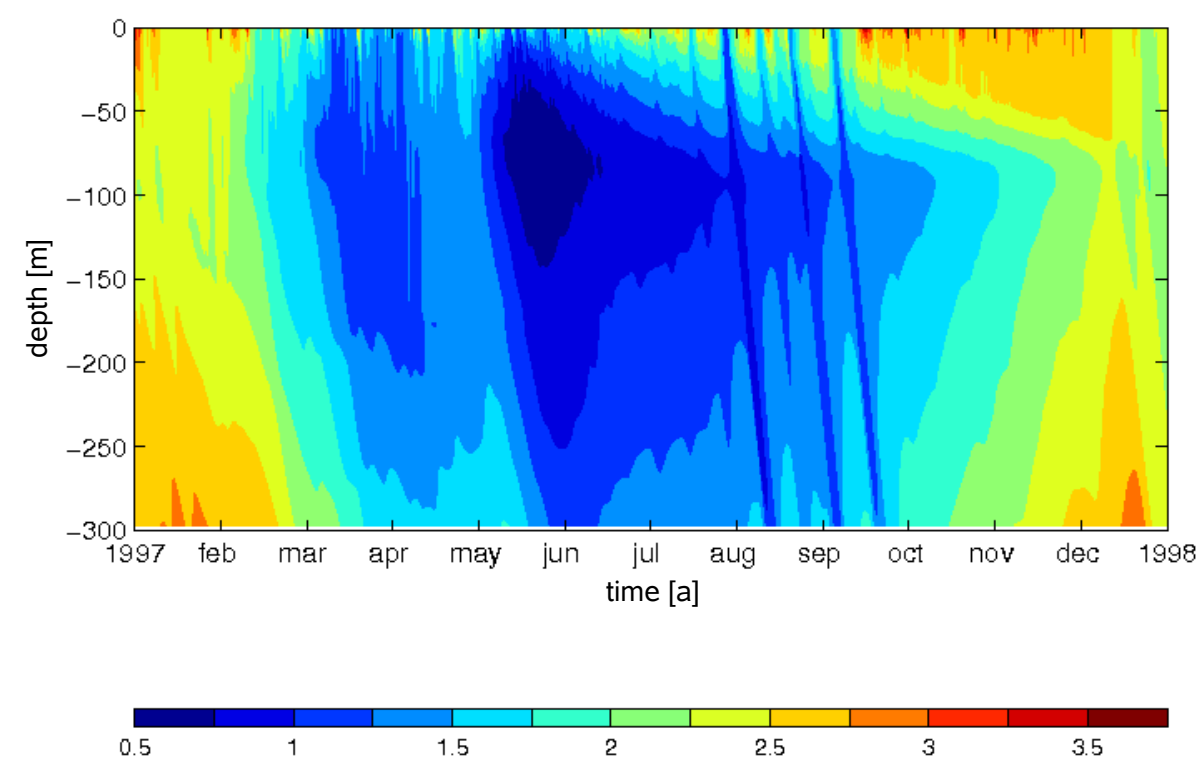

Fig. 7. Logarithm (base 10) of the residence time (in years) with respect to scavenging and colloid aggregation.

\section{Parameter sensitivity}

As for all numerical models, the particular solution depends on the choice of biogeochemical parameters. Some of the model parameterisations, e.g. for colloid aggregation, attempt to describe a complex process in a simple way. Estimation of the corresponding parameters therefore remains a major challenge. Even though some of the parameters of this study are based upon measurements taken in the laboratory and the ocean, most are approximations and some only pragmatic assumptions. It is therefore necessary to investigate the sensitivity of the model results to changes in the parameter values that are most uncertain.
Because of the large number of parameters involved, we limit the sensitivity tests to variations in one parameter at a time, leaving all other parameters unchanged (Table 2, Run A). We conducted two sensitivity runs per parameter, one with a 50\% lower and one with a $100 \%$ higher value. For purposes of comparison, we did the same with the zerodimensional model. The main effects of these parameter changes on dissolved iron concentrations are summarised in Table 4. 
Table 4. Change in modeled dFe concentration [\%] of the parameter sensitivity study with the one-dimensional model of the present study (1D) and the zero-dimensional model by Weber et al. (2005) (0D). Zero values correspond to changes smaller than $0.5 \%$. Surf $=$ upper $100 \mathrm{~m}$.

\begin{tabular}{|c|c|c|c|c|c|c|c|c|}
\hline \multirow[b]{2}{*}{ Parameter } & \multicolumn{2}{|c|}{ Surf Mean } & \multicolumn{2}{|c|}{ Surf Max } & \multicolumn{2}{|c|}{ Surf Min } & \multicolumn{2}{|c|}{250 Mean } \\
\hline & double & half & double & half & double & half & double & half \\
\hline \multicolumn{9}{|l|}{ 1D } \\
\hline$k_{\mathrm{sol}}$ & 20 & -10 & 51 & -26 & 17 & 9 & 4 & -2 \\
\hline$r_{\mathrm{Fe}: \mathrm{N}}$ & -4 & 3 & -3 & 2 & -5 & 3 & 2 & -1 \\
\hline$k_{\mathrm{ag}}$ & -5 & 3 & -4 & 2 & -8 & 4 & -4 & 2 \\
\hline$k_{\mathrm{col}}$ & -3 & 0 & 0 & 0 & -8 & 1 & -1 & 1 \\
\hline$k_{\mathrm{fel}}$ & 0 & -2 & 0 & -1 & 1 & -6 & 1 & -1 \\
\hline$k_{\mathrm{ld}}$ & 0 & 0 & 0 & 0 & 0 & -1 & 1 & -1 \\
\hline$k_{\mathrm{sca}}$ & 0 & 0 & 0 & 0 & 0 & 0 & 0 & 0 \\
\hline$k_{\mathrm{OX} 1}$ & 0 & 0 & 0 & 0 & 0 & 0 & 0 & 0 \\
\hline$k_{\mathrm{ox} 2}$ & 0 & 0 & 0 & 0 & 0 & 0 & 0 & 0 \\
\hline$k_{\mathrm{Ox} 3}$ & 0 & 0 & 0 & 0 & 0 & 0 & 0 & 0 \\
\hline$k_{\mathrm{ph} 1}$ & 0 & -2 & 0 & 0 & 1 & -7 & 1 & -1 \\
\hline$k_{\mathrm{ph} 2}$ & 2 & 0 & 1 & 0 & 6 & -1 & 1 & -1 \\
\hline$k_{\mathrm{ph} 3}$ & 0 & 0 & 0 & 0 & 0 & 0 & 0 & 0 \\
\hline$k_{\mathrm{ph} 4}$ & 0 & 0 & 0 & 0 & 1 & -1 & 0 & 0 \\
\hline$k_{\text {red }}$ & 0 & 0 & 0 & 0 & 0 & 0 & 0 & 0 \\
\hline \multicolumn{9}{|l|}{ OD } \\
\hline$k_{\mathrm{sol}}$ & 2 & -1 & 7 & -3 & 1 & 0 & - & - \\
\hline$r_{\mathrm{Fe}: \mathrm{N}}$ & -2 & 1 & -1 & 0 & -8 & 4 & - & - \\
\hline$k_{\mathrm{ag}}$ & -3 & 2 & 0 & 0 & -17 & 11 & - & - \\
\hline$k_{\mathrm{col}}$ & -1 & 1 & 0 & 0 & -4 & 5 & - & - \\
\hline$k_{\mathrm{fel}}$ & 0 & 0 & 0 & 0 & 1 & -3 & - & - \\
\hline$k_{\mathrm{ld}}$ & 0 & 0 & 0 & 0 & 0 & 0 & - & - \\
\hline$k_{\mathrm{sca}}$ & 0 & 0 & 0 & 0 & 0 & 0 & - & - \\
\hline$k_{\mathrm{ox} 1}$ & 0 & 0 & 0 & 0 & 0 & 0 & - & - \\
\hline$k_{\mathrm{ox} 2}$ & 0 & 0 & 0 & 0 & 0 & 0 & - & - \\
\hline$k_{\mathrm{ox} 3}$ & 0 & 0 & 0 & 0 & 0 & 0 & - & - \\
\hline$k_{\mathrm{ph} 1}$ & 1 & -1 & 0 & 0 & 5 & -4 & - & - \\
\hline$k_{\mathrm{ph} 2}$ & 0 & 0 & 0 & 0 & 0 & 0 & - & - \\
\hline$k_{\mathrm{ph} 3}$ & 0 & 0 & 0 & 0 & 0 & 0 & - & - \\
\hline$k_{\mathrm{ph} 4}$ & 1 & -1 & 0 & 0 & 8 & -8 & - & - \\
\hline$k_{\text {red }}$ & 0 & 0 & 0 & 0 & 0 & 0 & - & - \\
\hline
\end{tabular}

7.1 Comparison of parameter sensitivity between 0D and $1 \mathrm{D}$

Comparing the one-dimensional model results of the sensitivity study with model results of the same sensitivity study using the zero-dimensional model by Weber et al. (2005) (Table 4) reveals that both models are mainly sensitive to parameter changes of the main sources and sinks (solubility of atmospheric iron, colloidal aggregation and uptake by phytoplankton), whereas the one-dimensional model reacts even stronger. Changes in all other parameters are rather insignificant.

Model results of the zero-dimensional model indicate an important role of the vertical flux of iron due to the entrainment and detrainment of water during the annual cycle of mixed layer deepening and shoaling (Weber et al., 2005). This flux is dominant in the sense that it balances the other fluxes in such a way that the total dissolved iron concentration in the mixed layer does not depend strongly on the size of dust input, colloidal aggregation or uptake (Table 4), but remains tightly coupled to the concentration below the mixed layer, which is prescribed. In the one-dimensional model, iron profiles below the mixed layer have to be generated by the model itself (see also Sect. 5.1). This leads to bidirectional feedbacks. Changes in the surface fluxes are not necessarily compensated by the exchange with deeper water anymore and need to be balanced in other ways. However, the vertical exchange in the one-dimensional model can buffer the sensitivity of certain fluxes as well. The most distinct example of this is the solubility of atmospheric iron. One 
would expect that doubling $k_{\text {sol }}$ would increase [dFe] in the mixed layer by more than $20 \%$, bearing in mind that dust deposition is the main source of iron in the model. Here, the higher solubility of iron is buffered by changes in vertical iron fluxes in the same way than the interannual variability of dust deposition hardly influences the interannual consistency of $[\mathrm{dFe}]$ (see Sect. 6.2). The one-dimensional model confirms therefore the results by Weber et al. (2005), that the concentration of $\mathrm{dFe}$ in the mixed layer is strongly regulated by the concentration below the mixed layer.

\subsection{Atmospheric iron}

Estimates of the solubility of iron from dust vary between $0.1 \%$ and 50\%, (Zhuang et al., 1990; Duce and Tindale, 1991; Spokes and Jickells, 1996; Jickells and Spokes, 2001; Baker et al., 2006).

Changing the solubility of dust-deposited iron $\left(k_{\mathrm{sol}}\right)$ in the model has the strongest effect on $[\mathrm{dFe}]$ in surface waters of all parameters. In contrast to that, changes due to changes in $k_{\text {sol }}$ are rather small at depth.

The main deposition of atmospheric iron occurs in summer when the mixed layer is shallow and the mixed layer prevents exchange with deeper water. A higher solubility leads therefore to a higher accumulation of iron in the upper water column. The solubility of atmospheric iron influences the annual mean profile of [dFe] down to $200 \mathrm{~m}$ with the strongest effect at the surface and a decreasing effect with depth. Almost all atmospheric iron which dissolves forms FeL, since the formation of organic complexes is a faster process than the formation of colloids (see Sect. 6.1). Hence an increase in solubility leads to an increase in $[\mathrm{FeL}]$ and the additional iron is kept in solution. Winter mixing brings it down to $200 \mathrm{~m}$.

Increasing the solubility leads to an increase in both maximum and minimum $\mathrm{dFe}$ concentrations at the surface. As the spring minimum in dissolved iron is already quite high compared to observations, a solubility higher than about $2 \%$ at the BATS site seems unlikely.

\subsection{Iron uptake}

Changes in the maximum Fe:N-ratio in phytoplankton $\left(r_{\mathrm{Fe}: \mathrm{N}}\right)$ affect the uptake of iron by phytoplankton and the amount of iron released during remineralisation of detritus. At the parameter values used (Table 2, Run A) iron is never limiting to phytoplankton in the model, so that the actual Fe:N ratio in phytoplankton, zooplankton and detritus is always close to the maximum.

An increased uptake due to doubling of $r_{\mathrm{Fe}: \mathrm{N}}$, decreases the mean concentration of $\mathrm{dFe}$ in the surface by $4 \%$ on average. During the phytoplankton bloom in spring $[\mathrm{dFe}]$ can be up to $5 \%$ lower. The increased uptake on the other hand leads to an increase in deep dissolved iron concentrations (about $2 \%$ at $250 \mathrm{~m}$ depth) due to remineralisation of detritus.
This leads to a profile of $[\mathrm{dFe}]$ with a more pronounced difference between minimum concentrations at $50 \mathrm{~m}$ depth in the annual average and a local maximum below. Consequently, a smaller value of $r_{\mathrm{Fe}: \mathrm{N}}$ leads to less uptake, less remineralisation and more uniform $\mathrm{dFe}$ profile with less difference between minimum and maximum concentrations. Sedwick et al. (2005) observed even higher differences between minimum and maximum concentrations, both more extreme (Sect. 6.1). Hence, the model results may argue for a higher maximum Fe:N-ratio than initially allowed. This is consistent with $\mathrm{Wu}$ and Boyle (2002) and Bergquist and Boyle (2006), who estimate an Fe:C ratio for the North Atlantic which is larger than the Fe:C-ratio which Weber et al. (2005) used for their model to calculate the Fe:N-ratio. The North Atlantic may have elevated Fe:C ratios compared with most of the ocean owing to the higher surface $\mathrm{dFe}$ and luxury Fe uptake by organisms (Sunda and Huntsman, 1995).

\subsection{Colloids and ligands}

The parameters relating to organic complexes and colloids were discussed already in Sect. 5.2.

Changes in the colloidal aggregation rate $k_{\mathrm{ag}}$ affect the concentration of $\mathrm{dFe}$ almost uniformly throughout the profile. Doubling the value of $k_{\mathrm{ag}}$ leads to a $5 \%$ decrease of $[\mathrm{dFe}]$ in the upper $100 \mathrm{~m}$ and a $4 \%$ decrease below the mixed layer $(250 \mathrm{~m})$.

In our sensitivity experiments, the effect of changes in colloid formation, the scavenging rate or the strength of ligands on annual mean $[\mathrm{dFe}]$ is smaller (maximal $2 \%$ ) than that of changes in $k_{\mathrm{ag}}$. However, the speciation of iron is affected in different ways:

Changing the colloid formation rate $k_{\mathrm{col}}$ leads to a shift between $\mathrm{Fe}_{\mathrm{col}}$ and $\mathrm{FeL}$ throughout the whole profile, where, e.g. doubling the value of $k_{\mathrm{col}}$ leads to higher $\mathrm{Fe}_{\mathrm{col}}$ concentration (around $0.08 \mathrm{nM}$ ) and consequently to higher export fluxes through colloidal aggregation (approximately 88\% higher). This especially has an effect on the minimum concentration of $\mathrm{dFe}$ during the spring bloom, when detritus concentration, and therefore colloidal aggregation is highest. Doubling $k_{\mathrm{col}}$ reduces the annual minimum concentration in surface waters by $8 \%$.

Changing the ligand formation rate $k_{\text {fel }}$ leads to a shift between $\left[\mathrm{Fe}_{\mathrm{col}}\right]$ and $[\mathrm{FeL}]$ (around $0.05 \mathrm{nM}$ ), but mainly in the upper $200 \mathrm{~m}$, where higher $k_{\text {fel }}$ leads to higher [FeL] at the expense of $\left[\mathrm{Fe}_{\mathrm{col}}\right]$. The model is more sensitive to this value in the upper water column due to higher production of inorganic redox forms by photochemical processes at the expense of both $\left[\mathrm{Fe}_{\mathrm{col}}\right]$ and $[\mathrm{FeL}]$ during the day, but mainly subsequently through complexation by free organic ligands in the nighttime (see Sect. 6.1). This effect decreases with depth but reaches more than $200 \mathrm{~m}$ because of the deep winter mixing. In contrast, changing the ligand dissociation rate $k_{\mathrm{ld}}$ (and hence the stability constant) leads to a shift between $\mathrm{Fe}_{\mathrm{col}}$ and $\mathrm{FeL}$ only below the photic zone. A higher value 
of $k_{\text {ld }}$ leads to higher $\mathrm{Fe}_{\mathrm{col}}$ concentrations at the expense of [FeL] (up to around $0.08 \mathrm{nM}$ ). Below $50 \mathrm{~m}$, photochemical processes do not support organic complexation anymore.

Overall, the impact of changes of the parameters $k_{\mathrm{col}}, k_{\mathrm{fel}}$ and $k_{\mathrm{ld}}$ is small compared to that of changes in other parameters. A more detailed discussion of these processes has to await a significant reduction in the still substantial conceptual uncertainties, such as the parameterisation of colloidal aggregation.

\subsection{Photochemical processes}

Model results (Table 4) suggest that iron chemistry below the mixed layer is relatively insensitive to most parameter changes by a factor of two. This is especially true for all photochemically influenced processes since these have no immediate impact below the depth of penetration of light.

However, even in the upper $100 \mathrm{~m}$, changes in photochemical rate parameters have only a limited effect. While these processes are important in controlling iron speciation in the upper water column (Sect. 6.1), their influence on $[\mathrm{dFe}]$ is rather limited. This is because during the day, the photochemical processes are up to two orders of magnitude faster than all other processes. Reducing these rates by $50 \%$ slows down the cycle between $\mathrm{Fe}$ (III) and $\mathrm{Fe}$ (II)' but does not take away the dominance of these processes.

In contrast to the insensitivity to photoreduction of $\mathrm{Fe}(\mathrm{IIII})^{\prime}$ and $\mathrm{Fe}_{\mathrm{part}}\left(k_{\mathrm{ph} 3}\right.$ and $\left.k_{\mathrm{ph} 4}\right)$, the small (2\%) but finite sensitivity due to doubling or halving the photoreduction rates of $\mathrm{Fe}_{\mathrm{col}}$ and FeL $\left(k_{\mathrm{ph} 1}\right.$ and $\left.k_{\mathrm{ph}_{2}}\right)$ is due to the difference in the respective iron concentrations. $\mathrm{Fe}_{\mathrm{col}}$ and $\mathrm{FeL}$ are the dominant forms of iron in the mixed layer. Hence, doubling or halving their photoreduction rates has a greater impact.

The concentration difference of $\mathrm{dFe}$ is caused by a shift in the speciation of iron by changing $k_{\mathrm{ph} 1}$ or $k_{\mathrm{ph}_{2}}$. Doubling $k_{\text {ph1 }}$ leads to an increase of [FeL] at the expense of [ $\left.\mathrm{Fe}_{\mathrm{col}}\right]$ and vice versa. This allows iron to remain in solution longer by increasing $[\mathrm{FeL}]$, or increasing $\left[\mathrm{Fe}_{\mathrm{col}}\right]$ allowing higher export fluxes due to increased colloidal aggregation by increased $\mathrm{Fe}_{\mathrm{col}}$, which again results in decreased annual minimum of [dFe] of 6 to $7 \%$. This effect reaches down to $200 \mathrm{~m}$.

This is especially interesting for $k_{\mathrm{ph} 1}$, since the importance of photoreduction has been revealed in field studies using ferrihydrite as a model solid but there is a lack of data on naturally occurring colloids (Moffet, 2001). There is a need to quantify these parameters through laboratory and field studies to improve the model.

The model still has a relatively simplistic representation of photochemical reactions which are assumed to vary with irradiance over the visible band.

Recent deck-incubation experiments with open ocean water showed, that the UV part of the solar spectrum plays a major role in the photoreduction of iron, suggesting that any increases in UV (e.g. stratospheric ozone depletion) could increase the formation of $\mathrm{Fe}$ (II) and therefore the residence time and bioavailability of iron in the euphotic zone (Rijkenberg et al., 2005). However, in seawater UV is much more attenuated with depth than the visible band. In moderately productive water UV-B does not reach $10 \mathrm{~m}$ depth whereas visible light penetrates down to $50 \mathrm{~m}$ (Smith and Baker, 1979). Taking into consideration that doubling the photoreduction rates hardly influences the $\mathrm{dFe}$ concentration, an explicit consideration of UV in the model is of less relevance to the total iron concentration than to the speciation of iron in the upper water column.

\section{Introducing redissolution of particulate and colloidal iron}

The observed rapid formation of colloids and loss of [dFe] after pulsed iron additions (Nishioka et al., 2005) requires high aggregation rates. Lowering the colloid aggregation rate to reproduce the observed deep iron concentrations (Sect. 5.2) diminishes the possibility to reproduce such a temporal behaviour of iron concentrations within the mixed layer. The necessity to lower the aggregation rate is a consequence of the model setup in which there is no way back from particulate and/or colloidal iron to truly dissolved forms, other than photochemistry, which vanishes completely in the deep ocean.

An alternative to reducing the aggregation rate could therefore be to introduce leaching of particulate iron and/or colloidal iron back into dissolved form, as in Parekh et al. (2004). Desorption of iron bound to particle surfaces as well as disaggregation processes and break-up of colloids are not unlikely but the processes driving them and their rates are still not very well understood (Moffet, 2001).

To investigate the effect of redissolution on deep iron concentrations we add two additional source terms of iron in the equation for $\mathrm{Fe}(\mathrm{III})^{\prime}$ and the corresponding sinks in the equation for particulate iron $\left(\mathrm{Fe}_{p}\right)$ and colloidal iron $\left(\mathrm{Fe}_{\mathrm{col}}\right)$. The processes are parameterised as linearly dependent on the concentrations,

$\psi_{p}=k_{\mathrm{pd}}\left[\mathrm{Fe}_{p}\right]$

$\psi_{c}=k_{\mathrm{cd}}\left[\mathrm{Fe}_{\mathrm{col}}\right]$

with $\psi_{p}$ indicating the flux from $\mathrm{Fe}_{p}$ to $\mathrm{Fe}(\mathrm{III})^{\prime}$ and $\psi_{c}$ the flux from $\mathrm{Fe}_{\mathrm{col}}$ to $\mathrm{Fe}(\mathrm{III})^{\prime}$.

In the absence of information regarding rates for these processes, we choose rates that are of the same order of magnitude as photochemical dissolution rates in the mixed layer, $k_{\mathrm{pd}}=k_{\mathrm{cd}}=0.2 d^{-1}$. Both are probably at the very upper end of possible rates, and are also significantly higher than estimates by Parekh et al. (2004) $\left(20-100 y^{-1}\right)$. However, the slow redissolution rate in Parekh et al. (2004) complements an equally slow scavenging rate, while we also attempt to represent faster processes.

We performed three additional experiments with redissolution, one including $\psi_{p}$ (Run r1), one with $\psi_{c}$ (Run r2), 
and one with both processes (Run r3). For these experiments the initial colloidal aggregation rate by Weber et al. (2005) is used, while the conditional stability constant of iron binding ligands is taken from the present study (Run A). This allows comparison of the results of this experiment with results from Run A.

In all three experiments, dissolved iron concentrations are increased with respect to the case of the initial model run (Run I) (Fig. 8). Compared to run I, the introduction of $\psi_{p}$ (Run r1) leads to a more pronounced profile with a concentration minimum at $50 \mathrm{~m}$ depth and a local maximum below. Such a profile comes closer to observed profile characteristics (Sect. 6.1). The dFe losses in run $\mathrm{r} 1$ are smaller and do not lead to iron depletion at depth like in run I. Nevertheless, the annual mean $\mathrm{dFe}$ concentration at the surface is relatively low $(0.29 \mathrm{nM})$. The introduction of $\psi_{c}$ (Run $\left.\mathrm{r} 2\right)$ creates similar model results as Run A without the need to reduce the colloidal aggregation rate. Additionally, the profile of [dFe] has a more pronounced difference between minimum concentrations at $50 \mathrm{~m}$ depth in the annual average and a local maximum below compared to Runs I and A. The profile of [dFe] in Run r3 is similar to that of run r2, with slightly elevated values. In that run, $\psi_{c}$ dominates over $\psi_{p}$ since most of the dissolved iron passes the colloidal iron pool before being scavenged or aggregated. This explains the relatively small effect of $\psi_{p}$ in that run, compared to the large effect in run r1.

It is probable that by varying the colloid aggregation and redissolution rates simultaneously over the range of values considered here, a solution can be found that reproduces both the observed deep iron concentrations and the rapid removal of iron from the dissolved phase in iron fertilisation experiments. However, such a systematic parameter study is outside the scope of the present paper. Introducing $k_{\mathrm{pd}}$ and/or $k_{\mathrm{cd}}$ might be especially interesting for future model studies with pulsed events, such as iron fertilisation experiments. However, such an improvement of the model will need further input from laboratory and field experiments with regards to the processes and rates an which redissolution of iron from colloids and the surface of sinking particles take place.

\section{Conclusions}

A one-dimensional version of an earlier model for iron speciation and biogeochemistry by Weber et al. (2005) was set up. We have demonstrated that the model, using parameter values guided by laboratory and field studies, is able to simulate the temporal patterns and the vertical profile of dissolved iron in the upper ocean for the Bermuda Atlantic Time series Study site reasonably well. However, the model solution still depends strongly on the choice of some biogeochemical parameters. The main outcomes of this study are:

1. High colloidal aggregation rates of iron, observed in particle-rich coastal waters (Wen et al., 1997) and dur-

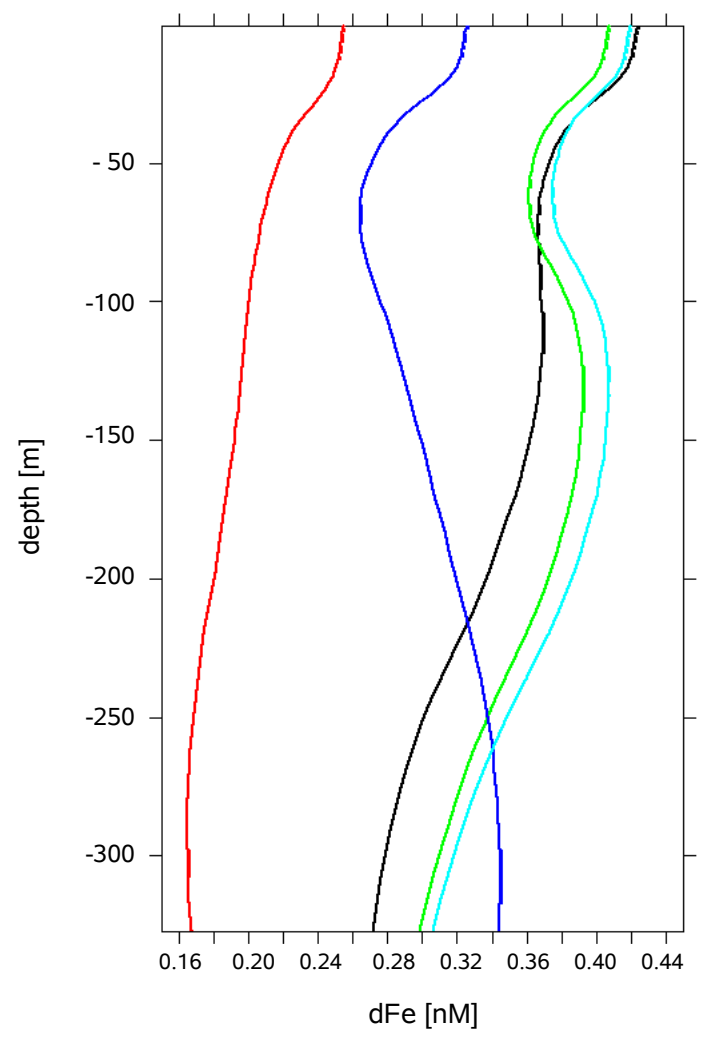

Fig. 8. Annual mean profile of modeled dFe concentration: Run I (red), Run A (black), Run r1 with $k_{\mathrm{pd}}$ (blue), Run r2 with $k_{\mathrm{cd}}$ (green) and Run $\mathrm{r} 3$ with $k_{\mathrm{pd}}$ and $k_{\mathrm{cd}}$ (cyan).

ing iron fertilisation experiments (Nishioka et al., 2005) can not be applied to reproduce iron profiles at the BATS site with the current model. To prevent unrealistic depletion of dissolved iron at depth, the model requires aggregation rates one order of magnitude lower than those extrapolated from observations at higher particle concentrations. Introducing a hypothetical redissolution of colloids or of iron bound to sinking particle surfaces also leads to less depletion of dissolved iron at depth in the model.

2. A relatively strong iron binding ligand is required in the model, especially at depth, to prevent dissolved iron from aggregation and scavenging and to maintain a realistic iron profile. The required value for the conditional stability constant depends on the rate chosen for colloidal formation and is at the higher end of observed values.

3. The residence time for iron with respect to scavenging and colloid aggregation depends strongly on depth and time through the distribution of particles. Because of their larger abundance at the BATS site, biological particles dominate the loss of iron in the mean. Episodic 
inputs of aeolian particles from dust deposition events can, however, lead to brief but strong reductions in residence time. Typical values for the residence time below a few hundred meter are on the order of a hundred years.

4. The solubility of atmospherically deposited iron has a strong influence on the surface $\mathrm{dFe}$ concentration, especially in summer. Solubilities of more than $2 \%$ lead to modeled $\mathrm{dFe}$ concentrations that are higher than observations.

5. In the upper water column, the dominant processes affecting iron speciation are the photochemically driven redox-reactions of inorganic $\mathrm{Fe}$ and organic complexation. These manifest themselves as a strong daily cycle of iron and reactive oxygen speciation in the mixed layer. These processes act on such short timescales that vertical gradients within the mixed layer are produced that are strongest for the very short-lived species such as superoxide and ferrous iron and somewhat weaker for longer-lived species, such as hydrogen peroxide. Both determine the residence time of dissolved iron in the euphotic zone by keeping iron in solution and therefore preventing it from scavenging. This is manifested as a dissolved iron profile with higher concentration at the surface and a strong decrease in the upper $50 \mathrm{~m}$ following the decreasing light availability.

The conclusions are based on a still very limited data set. Further measurements, especially time series of dissolved iron and its speciation, would be extremely helpful to validate the model. The sensitivity of the model to slight changes in the parametrisation of still unclear processes indicates that we are far away from understanding the influence of iron in the marine ecosystem and to predict it with confidence in global climate models.

\section{Appendix A}

In addition to the chemical iron model by Weber et al. (2005) and the optimised NPZD ecosystem model by Oschlies and Schartau (2005) we implemented three further biological model equations that determine the evolution of the concentration of iron in phytoplankton $\mathrm{P}_{\mathrm{Fe}}$, detritus $\mathrm{D}_{\mathrm{Fe}}$, and zooplankton $\mathrm{Z}_{\mathrm{Fe}}$. The equations are based on the NPZD model by Oschlies and Schartau (2005) and are formulated in units of $\mathrm{nM}$ iron $\mathrm{d}^{-1}$.

$$
\begin{aligned}
\frac{d}{d t}\left[\mathrm{P}_{\mathrm{Fe}}\right]= & Q \rho[\mathrm{P}]-Q G([\mathrm{P}])[\mathrm{Z}]-\gamma_{p}(T)\left[\mathrm{P}_{\mathrm{Fe}}\right]- \\
& Q \gamma_{p^{2}}[\mathrm{P}]^{2} \\
\frac{d}{d t}\left[\mathrm{Z}_{\mathrm{Fe}}\right]= & Q \gamma_{z a} G([\mathrm{P}])[\mathrm{Z}]-\gamma_{z b}(T)\left[\mathrm{Z}_{\mathrm{Fe}}\right]- \\
& \gamma_{\mathrm{fe}: \mathrm{z}{ }_{z^{2}}}[\mathrm{Z}]^{2}
\end{aligned}
$$

$$
\begin{aligned}
\frac{d}{d t}\left[\mathrm{D}_{\mathrm{Fe}}\right]= & Q \gamma_{p^{2}}[\mathrm{P}]^{2}+Q\left(1-\gamma_{z a}\right) G([\mathrm{P}])[\mathrm{Z}]+ \\
& r_{\mathrm{fe}: \mathrm{z}} \gamma_{z^{2}}[\mathrm{Z}]^{2}-\gamma_{d}(T)\left[\mathrm{D}_{\mathrm{Fe}}\right]-\mathrm{w}_{\mathrm{s}} \frac{\mathrm{d}\left[\mathrm{D}_{\mathrm{Fe}}\right]}{\mathrm{dz}}
\end{aligned}
$$

with $Q=\left[\mathrm{P}_{\mathrm{Fe}}\right] /[\mathrm{P}]$ and $r_{\mathrm{fe}: \mathrm{z}}=\left[\mathrm{Z}_{\mathrm{Fe}}\right] /[\mathrm{Z}]$.

The terms on the right hand side are identical to the terms in the NPZD model except for a multiplication with either $Q$ or $r_{\text {fe:z. }}$. One exception is the uptake of iron by phytoplankton: While the growth rate of phytoplankton $\mu$ is the smaller of either a nutrient-, a light-, or an iron-limited rate $\mu=\min \left(\mu_{\mathrm{N}}, \mu_{\mathrm{L}}, \mu_{\mathrm{Fe}}\right)$ with $\mu_{\mathrm{Fe}}=\mu^{*}\left(Q-Q_{\min }\right) / Q, \rho$ does not depend on light, but on iron concentration in the medium through $\rho=$ $\min \left(\mu_{\mathrm{N}}, \rho_{\mathrm{Fe}}\right)$, where $\rho_{\mathrm{Fe}}=\mu^{*}[\mathrm{sFe}] /\left(K_{\mathrm{Fe}}+[\mathrm{sFe}]\right)$ has the standard Michaelis-Menten dependency on iron availability. $\mu^{*}$ is the (temperature-dependent) maximum growth rate. sFe refers to truly dissolved iron (FeL, $\left.\left.\mathrm{Fe}(\mathrm{III})^{\prime}\right) \mathrm{Fe}(\mathrm{III})^{\prime}\right)$.

Acknowledgements. We would like to thank N. Gruber, E. Achterberg and two anonymous reviewers for their helpful comments. This work was partly funded by the DFG project OS 175/3-1 and the BMBF project SOPRAN (Surface Ocean Processes in the Anthropocene).

Edited by: J. Middelburg

\section{References}

Baker, A., Jickells, T., Witt, M., and Linge, K.: Trends in the solubility of iron, aluminium, manganese and phosphorus in aerosol collected over the Atlantic Ocean, Mar. Chem., 98, 43-58, 2006.

Barbeau, K. and Moffett, J.: Dissolution of iron oxides by phagotrophic protists: Using a novel method to quantify reaction rates, Environ. Sci. Technol., 32, 2969-2975, 1998.

Barbeau, K., Rue, E., Trick, C., Bruland, K., and Butler, A.: Photochemical reactivity of siderophores produced by marine heterotrophic bacteria and cyanobacteria based on characteristic Fe(III) binding groups, Limnol. Oceanogr., 48, 1069-1078, 2003.

Baskaran, M., Santschi, P., Benoit, G., and Honeyman, B.: Scavenging of thorium isotopes by colloids in seawater of the Gulf of Mexico, Geochimica et Cosmochimica Acta, 56, 3375-3388, 1992.

Bergquist, B. and Boyle, E.: Dissolved iron in the tropical and subtropical Atlantic Ocean, Global Biogeochem. Cy., 20, GB1015, doi:10.1029/2005GB002 505, 2006.

Brock, T. D.: Calculating solar radiation for ecological studies, Ecol. Model., 14, 1-19, 1981.

Bruggeman, J., Burchard, H., Kooi, B., and Sommeijer, B.: A second-order, unconditionally stable, mass-conserving integration scheme for biochemical systems, Appl. Numer. Math., 57, 36-58, 2006.

Burchard, H., Deleersnijder, E., and Meister, A.: Application of Modified Patankar schemes to stiff biogeochemical models for the water column, Ocean Dynam., 55, 326-337, 2005.

Burchard, H., Bolding, K., Kuehn, W., Meister, A., Neumann, T., and Umlauf, L.: Description of a flexible and extendable 
physical-biogeochemical model system for the water column, J. Mar. Syst., 61, 180-211, 2006.

Carlson, C., Ducklow, H. W., and Michaels, A. F.: Annual flux of dissolved organic-carbon from the euphotic zone in the northwestern Sargasso Sea, Nature, 371, 405-408, 1994.

Cheng, Y., Canuto, V. M., and Howard, A. M.: An improved model for the turbulent PBL, J. Atmos. Sci., 59, 1550-1565, 2002.

Cullen, J., Berquist, B., and Moffett, J.: Thermodynamic characterization of partitioning of iron between soluble and colloidal species in the Atlantic Ocean, Mar. Chem., 98, 295-303, 2006.

Doney, S., Najjar, R., and Stewart, S.: Photochemistry, mixing and diurnal cycles in the upper ocean, J. Mar. Res., 53, 341-369, 1995.

Droop, M. R.: 25 years of algal growth kinetics: a personal view, Botanica Marina, 26, 99-112, 1983.

Duce, R. and Tindale, N.: Atmospheric transport of iron and its deposition in the ocean, Limnol. Oceanogr., 36, 1715-1726, 1991.

Dutkiewicz, S., Follows, M. J., and Parekh, P.: Interactions of the iron and phosphorus cycles: A three-dimensional model study, Global Biogeochem. Cy., 19, 1-22, 2005.

Emmenegger, L., Schönberger, R., Sigg, L., and Sulzberger, B.: Light-induced redox cycling of iron in circumneutral lakes, Limnol. Oceanogr., 46, 49-61, 2001.

Fung, I., Meyn, S., Tegen, I., Doney, S., John, J., and Bishop, J.: Iron supply and demand in the upper ocean, Global Biogeochem. Cy., 14, 281-301, 2000.

Gledhill, M. and van den Berg, C.: Determination of complexation of iron(III) with natural organic complexing ligands in seawater using cathodic stripping voltammetry, Mar. Chem., 47, 41-54, 1994.

Jerlov, N.: Optical oceanography, Elsevier, 1968.

Jickells, T. and Spokes, L.: Atmospheric iron inputs to the oceans, in: The Biogeochemistry of Iron in Seawater, edited by: Turner, D. and Hunter, K., SCOR/IUPAC Series, J. Wiley, 85-121, 2001.

Johnson, K., Coale, K., Elrod, V., and Tindale, N.: Iron photochemistry in seawater from the equatorial Pacific, Mar. Chem., 46, 319-334, 1994.

Johnson, K., Gordon, R., and Coale, K.: What controls dissolved iron concentrations in the world ocean?, Mar. Chem., 57, 137$161,1997$.

King, D., Aldrich, R., and Charniecki, S.: Photochemical redox cycling of iron in $\mathrm{NaCl}$ solutions, Mar. Chem., 44, 105-120, 1993.

Kuma, K., Nakabayashi, S., Suzuki, Y., Kudo, I., and Matsunaga, K.: Photo-reduction of Fe(III) by dissolved organic substances and existence of $\mathrm{Fe}(\mathrm{II})$ in seawater during spring blooms, Mar. Chem., 37, 15-27, 1992.

Mahowald, N., Luo, C., Del Corral, J., and Zender, C.: Interannual variability in atmospheric mineral aerosols from a 22-year model simulation and observational data, J. Geophys. Res., 108(D12), 4352, doi:10.1029/2002JD002821, 2003.

McClain, C. and Firestone, J.: An investigation of Ekman upwelling in the North Atlantic, J. Geophys. Res., 98, 12 327-12 339, 1993.

Moffet, J.: Transformations among different forms of iron in the ocean, in: The Biogeochemistry of Iron in Seawater, edited by: Turner, D. and Hunter, K., SCOR/IUPAC Series, J. Wiley, 1-7, 2001.

Moran, S. B. and Buesseler, K. O.: Short residence time of colloids in the upper ocean off Bermuda, Nature, 359, 221-223, 1992.

Musgrave, D., Chow, J., and Jenkins, W.: Application of a model of upper-ocean physics for studying seasonal cycles of oxygen, J. Geophys. Res., 93, 15 679-15 700, 1988.

Nishioka, J., Takeda, S., de Baar, H. J., Croot, P. L., Boye, M., Laan, P., and Timmermans, K. R.: Changes in the concentration of iron in different size fractions during an iron enrichment experiment in the open Southern Ocean, Mar. Chem., 95, 51-63, 2005.

Obernosterer, I., Ruardij, P., and Herndl, G.: Spatial and diurnal dynamics of dissolved organic matter (DOM) fluorescence and $\mathrm{H}_{2} \mathrm{O}_{2}$ and the photochemical demand of surface water DOM across the subtropical Atlantic Ocean, Limnol. Oceanogr., 46, 632-643, 2001.

Ono, S., amd R.G. Najjar, A. E., and Bates, N.: Shallow remineralization in the Sargasso Sea estimated from seasonal variations in oxygen, dissolved inorganic carbon and nitrate, Deep-Sea Res. II, 48, 1567-1582, 2001.

Oschlies, A. and Schartau, M.: Basin-scale performance of a locally optimized marine ecosystem model, J. Mar. Res., 63, 335-358, 2005.

Parekh, P., Follows, M., and Boyle, E.: Modelling the global ocean iron cycle, Global Biogeochem. Cy., 18, GB1002, doi: 1029/2003GB002061, 2004.

Paulson, C. A. and Simpson, J. J.: Irradiance measurements in the upper ocean, J. Phys. Oceanogr., 7, 952-956, 1977.

Rijkenberg, M., Fischer, A., Kroon, J., Gerringa, L., Timmermans, K., Wolterbeek, H., and de Baar, H.: The influence of UV irradiation on the photoreduction of iron in the Southern Ocean, Mar. Chem., 93, 119-129, 2005.

Rijkenberg, M. J. A., Gerringa, L. J. A., Neale, P. J., Timmermans, K. R., Buma, A. G. J., and Baar, H. J. W. d.: UVA variability overrules UVB ozone depletion effects on the photoreduction of iron in the Southern Ocean, Geophys. Res. Lett., 31, 1-5, 2004.

Rose, A. and Waite, T.: Predicting iron speciation in coastal waters from the kinetics of sunlight-mediated iron redox cycling, Aquat. Sci., 65, 375-383, 2003.

Rue, E. and Bruland, K.: Complexation of iron(III) by natural organic ligands in the Central North Pacific as determined by a new competitive ligand equilibration / adsorptive cathodic stripping voltammetric method, Mar. Chem., 50, 117-138, 1995.

Schartau, M. and Oschlies, A.: Simultaneous data-based optimization of a 1D-ecosystem model at three locations in the North Atlantic: Part I - Method and parameter estimates, J. Mar. Res., 61, 765-793, 2003.

Sedwick, P., Church, T., Bowie, A., Marsay, C., Ussher, S., Achilles, K., Lethaby, P., Johnson, R., Sarin, M., and McGillicuddy, D.: Iron in the Sargasso Sea (BATS region) during summer: Eolian imprint, spatiotemporal variability, and ecological implications, Global Biogeochem. Cy., 19, GB4006, doi:10.1029/2004GB002445, 2005.

Smith, R. and Baker, K.: Penetration of UV-B and biologically effective dose-rates in natural waters, Photochem. Photobiol., 29, 311-323, 1979.

Spokes, L. and Jickells, T.: Factors controlling the solubility of aerosol trace metals in the atmosphere and on mixing into seawater, Aquat. Geochem., 1, 355-374, 1996.

Steinberg, D., Carlson, C., Bates, N., Johnson, R. J., and Michaels, A. A. K.: Overview of the US JGOFS Bermuda Atlantic Timeseries Study (BATS): A decade-scale look at ocean biology and biogeochemistry, Deep-Sea Res. II, 48, 1405-1447, 2001.

Sunda, W. and Huntsman, S.: Iron uptake and growth limitation in 
oceanic and coastal phytoplankton, Mar. Chem., 50, 189-206, 1995.

Umlauf, L. and Burchard, H.: Second-order turbulence models for geophysical boundary layers. A review of recent work, Cont. Shelf Res., 25, 795-827, 2005.

Uppala, S., Kallberg, P., Simmons, A., Andrae, U., da Costa Bechtold, V., Fiorino, M., Gibson, J., Haseler, J., Hernandez, A., Kelly, G., Li, X., Onogi, K., Saarinen, S., Sokka, N., Allan, R., Andersson, E., Arpe, K., Balmaseda, M., Beljaars, A., van de Berg, L., Bidlot, J., Bormann, N., Caires, S., Chevallier, F., Dethof, A., Dragosavac, M., Fisher, M., Fuentes, M., Hagemann, S., Holm, E., Hoskins, B., Isaksen, L., Janssen, P., Jenne, R., McNally, A., Mahfouf, J.-F., Morcrette, J.-J., Rayner, N., Saunders, R., Simon, P., Sterl, A., Trenberth, K., Untch, A., Vasiljevic, D., Viterbo, P., and Woollen, J.: The ERA-40 re-analysis, Q. J. Roy. Meteor. Soc., 131, 2961-3012, 2005.

Van den Berg, C.: Evidence for organic complexation of iron in seawater, Mar. Chem., 50, 139-157, 1995.

Voelker, B. and Sedlak, D.: Iron reduction by photoproduced superoxide in seawater, Mar. Chem., 50, 93-102, 1995.

Waite, T. and Morel, F.: Photoreductive dissolution of colloidal iron oxides in natural waters, Environ. Sci. Technol., 18, 860-868, 1984.

Watson, A.: Iron limitation in the ocean, in: The Biogeochemistry of Iron in Seawater, edited by: Turner, D. and Hunter, K., SCOR/IUPAC Series, J. Wiley, Chichester, 9-39, 2001.

Weber, L., Völker, C., Schartau, M., and Wolf-Gladrow, D.: Modeling the speciation and biogeochemistry of iron an the Bermuda Atlantic Timeseries Study site, Global Biogeochem. Cy., 19, GB1019, doi:10.1029/2004GB002340, 2005.

Wells, M.: Marine Colloids and Trace Metals, in: Marine Dissolved Organic Matter, edited by: Hansell, D. A. and Carlson, C. A., Academic Press, Elsevier, 367-404, 2002.
Wells, M. and Mayer, L.: The photoconversion of colloidal iron oxyhydroxides in seawater, Deep-Sea-Res., 38, 1379-1395, 1991.

Wen, L.-S., Santschi, P., and Tang, D.: Interactions between radioactively labeled colloids and natural particles: Evidence for colloidal pumping, Geochimica et Cosmochimica Acta, 61, 2867-2878, 1997.

Witter, A. and Luther III, G.: Variation in Fe-organic complexation with depth in the northwestern Atlantic Ocean as determined using a kinetic approach, Mar. Chem., 62, 241-258, 1998.

Witter, A., Hutchins, D., Butler, A., and Luther III, G.: Determination of conditional stability constants and kinetic constants for strong model Fe-binding ligands in seawater, Mar. Chem., 69, $1-17,2000$.

$\mathrm{Wu}$, J. and Boyle, E.: Determination of iron in seawater by high-resolution isotope dilution inductively coupled plasma mass spectrometry after $\mathrm{Mg}(\mathrm{OH})_{2}$ coprecipitation, Analytica Chimica Acta, 367, 183-191, 1998.

$\mathrm{Wu}$, J. and Boyle, E.: Iron in the Sargasso Sea: Implications for the processes controlling dissolved $\mathrm{Fe}$ distribution in the ocean, Global Biogeochem. Cy., 16, 1086, doi:10.1029/ 2001GB001453, 2002.

Wu, J. and Luther III, G.: Size-fractionated iron concentrations in the water column of the western North Atlantic Ocean, Limnol. Oceanogr., 39, 1119-1129, 1994.

$\mathrm{Wu}$, J. and Luther III, G.: Complexation of Fe(III) by natural organic ligands in the Northwest Atlantic Ocean by a competitive ligand equilibration method and a kinetic approach, Mar. Chem., 50, 159-177, 1995.

Wu, J., Boyle, E., Sunda, W., and Wen, L.-S.: Soluble and colloidal iron in the oligotrophic North Atlantic and North Pacific, Science, 293, 847-849, 2001.

Zhuang, G., Duce, R., and Kester, D.: The dissolution of atmospheric iron in the surface seawater of the open ocean, J. Geophys. Res., 95, 16207-16216, 1990. 